\title{
Assimilation of Chinese Doppler Radar and Lightning Data Using WRF-GSI: A Case Study of Mesoscale Convective System
}

\author{
Yi Yang, ${ }^{1}$ Ying Wang, ${ }^{1}$ and Kefeng $\mathrm{Zhu}^{2}$ \\ ${ }^{1}$ Key Laboratory of Arid Climatic Changing and Reducing Disaster of Gansu Province, College of Atmospheric Sciences, \\ Lanzhou University, No. 222 TianShui South Road, Lanzhou City, Gansu 730000, China \\ ${ }^{2}$ Key Laboratory for Mesoscale Severe Weather/MOE and School of Atmospheric Sciences, Nanjing University, No. 22 Hankou Road, \\ Nanjing city, Jiangsu 210093, China
}

Correspondence should be addressed to Yi Yang; yangyi@lzu.edu.cn

Received 12 May 2014; Revised 9 September 2014; Accepted 15 September 2014

Academic Editor: Bala Subrahamanyam

Copyright (C) 2015 Yi Yang et al. This is an open access article distributed under the Creative Commons Attribution License, which permits unrestricted use, distribution, and reproduction in any medium, provided the original work is properly cited.

\begin{abstract}
The radar-enhanced GSI (version 3.1) system and the WRF-ARW (version 3.4.1) model were modified to assimilate radar/lightningproxy reflectivity. First, cloud-to-ground lightning data were converted to reflectivity using a simple assumed relationship between flash density and reflectivity. Next, the reflectivity was used in the cloud analysis of GSI to adjust the cloud/hydrometeors and moisture. Additionally, the radar/lightning-proxy reflectivity was simultaneously converted to a 3D temperature tendency. Finally, the model-calculated temperature tendencies from the explicit microphysics scheme, as well as cumulus parameterization at 3D grid points at which the radar temperature tendency is available, were updated in a forward full-physics step of diabatic digital filter initialization in the WRF-ARW. The WRF-GSI system was tested using a mesoscale convective system that occurred on June 5, 2009, and by assimilating Doppler radar and lightning data, respectively. The forecasted reflectivity with assimilation corresponded more closely to the observed reflectivity than that of the parallel experiment without assimilation, particularly during the first $6 \mathrm{~h}$. After assimilation, the short-range precipitation prediction improved, although the precipitation intensity was stronger than the observed one. In addition, the improvements obtained by assimilating lightning data were worse than those from assimilating radar reflectivity over the first $3 \mathrm{~h}$ but improved thereafter.
\end{abstract}

\section{Introduction}

The development of nonhydrostatic numerical weather prediction (NWP) models with high resolutions, together with computational advances, has made refined weather forecasting possible. At present, however, sounding and satellite data cannot provide sufficient mesoscale or small-scale information to generate the initial field of the NWP model. The high temporal and spatial resolution of Doppler radar data provide not only the location and intensity of precipitation, but also the movement of hydrometeors, which are essential inputs to the initial field in a mesoscale NWP model. Nevertheless, ground-based Doppler radar has three main disadvantages. First, the detection range is limited to the scanning radius. Second, as most detection is limited to land, there are few observations of convective systems at sea. Finally, detection can be easily affected by terrain shadowing in mountainous regions. These disadvantages cause some difficulties when using radar data for the initialization of a refined forecast model. Recently, the rapid development of the lightning location network has provided a way of overcoming these drawbacks. Lightning is an indicator of deep convection, and lightning location network data can provide detailed information on convective clouds, such as the time, location, flash number, polarity, and intensity of discharge events. Furthermore, lightning data are relatively unaffected by geographical constraints and exhibit a higher temporal and spatial resolution than meteorological radar observations. Thus, lightning location network data can play an important role in convective weather research by supplementing radar data in the initialization of refined weather forecasting. Using both radar and lightning data would allow their complementary advantages to improve the accuracy of the representation of convective systems in the 
initial field of a model and could thus play an important role in increasing the accuracy of short-range convective weather forecasting. However, such an approach has not been widely studied.

Worldwide, there have been many studies of the methods that can be used to assimilate Doppler radar reflectivity. The principal methods used are the variational method [16 ] and the ensemble Kalman filter [7-10], together with some empirical methods, such as cloud analysis [11-15] and physical initialization [16-18]. Research into assimilating data from lightning location networks has begun recently, but there have been relatively few studies compared with those that focus on assimilating other meteorological data. The difficulty in assimilating lightning data is that the observational variable is not one of the variables incorporated into the models; thus it must be connected with a model variable or a diagnosed variable before assimilation. Alexander et al. and Chang et al. $[19,20]$ used lightning data provided by the National Lightning Detection Network, using microwave imaging data for adjustment and regression, to simulate continuous convective precipitation information in blind regions (e.g., at sea) or time periods (e.g., between overpasses of two satellites). These studies generated impressive improvements in simulations of the superstorm in 1993 and the Groundhog Day rainstorm in 1998 by assimilating the lightning data into a model to adjust the latent heat profile using a nudging method. However, the correlation between lightning and precipitation rate varies according to region and climate, which leads to some uncertainties when assimilating lightning data in this way. Some studies have revealed that a high correlation exists between convective rainfall and the humidity profile [21]. Gallus and Segal [22] noted that adding humidity information in areas where the radar reflectivity is high and the humidity is low can improve forecasting skill. Lightning is an indicator of convective weather, because lightning occurs where there is strong convection. The atmospheric model describes convective processes with a cumulus parameterization; if lightning data are used to trigger (or to suppress) cumulus parameterization and to adjust the humidity profile, then an improved initial field will be achieved.

Papadopoulos et al. [23] studied cloud-to-ground lightning data assimilation into BMJ (Betts-Miller-Janjic) cumulus parameterization. In this scheme, it is assumed that convective processes cannot be produced by the cumulus parameterization if subgrid perturbations are insufficiently large or if the simulated humidity is lower than the actual humidity. So, in their assimilation method, lightning data are used to indicate the location of deep moist convection in the simulated region. Papadopoulos et al. nudged the simulated humidity profile towards the profile found from an inverse method applied to lightning observations and then used the adjusted profile to calculate the latent heat profile, which is linked to the local environment in the cumulus parameterization process. Using this method, an impressive improvement was achieved in the precipitation forecast. Gallus and Segal [22] compared the effects of differing BMJ and KF (Kain-Fritsch) parameterizations on initialization in a cold pool and found that the KF parameterization performed better than the BMJ parameterization. Mansell et al. [24] researched the effect of lightning data assimilation on KF cumulus parameterization. In their scheme, where the lightning number at a grid point reaches or exceeds the threshold value but the KF scheme is not activated, $\mathrm{KF}$ cumulus parameterization is forced into activation, and the humidity is nudged accordingly. In contrast, where the lightning number is lower than the threshold value, KF cumulus parameterization is partly or completely suppressed. In addition, Benjamin et al. [11, 25] converted lightning data into 3D proxy reflectivity in the RUC (rapid update cycle) cloud analysis procedure, which is based on a simple assumed relationship between flash density and reflectivity in the GSI (Grid-point Statistics Interpolation) system. Based on this approach, it is possible to assimilate lightning data in the same way as that of radar reflectivity data. Furthermore, the combined reflectivity (the radar reflectivity and proxy reflectivity converted from lightning data) was used to adjust microphysical variables and water vapor and also to calculate the temperature tendency, which was updated in the forward full-physics step of diabatic digital filter initialization (DDFI) in WRF (Weather Research and Forecasting)-ARW (advanced research WRF). Benjamin et al. suppressed cumulus parameterization in the area without reflectivity. This type of lightning data assimilation method is currently being used in the RR (rapid refresh) system. Their results revealed that, in most coastal areas with no radar, lightning data are the main observations of convective systems and significantly improve forecasts in regions such as the $\mathrm{Hu}$ et al. $[13,26]$. There have been several case studies that focus primarily on the three methods outlined above [27-30].

The RUC/RR procedure has been used to assimilate lightning-proxy reflectivity transformed from lightning data based on the GSI cloud analysis system and appears to work very successfully. However, in the GSI (version 3.1) system released by the DTC (Development Testbed Center) and, in WRF-ARW (version 3.4.1), the function that assimilates radar/lightning-proxy reflectivity is not activated. In this paper, the GSI system and WRF-ARW are modified to assimilate radar/lightning-proxy reflectivity as in RUC/RR. We compare the assimilation of cloud-to-ground lightning data and Doppler radar data from Hefei in Anhui Province using the WRF-GSI system to examine the effect of the revised system.

The remainder of this paper is organized as follows. Section 2 describes the cloud analysis system in the GSI system and the digital filter initialization in WRFARW, Section 3 presents the data and experimental design, Section 4 provides an analysis of the results, and Section 5 presents a summary of the results.

\section{Cloud Analysis System in the GSI and Digital Filter Initialization of the WRF-ARW Model}

In the GSI radar-enhanced cloud analysis system, 3D-grid cloud cover and precipitation types are set up using GOESNESDIS (GOESTATIONARY-The National Environmental 


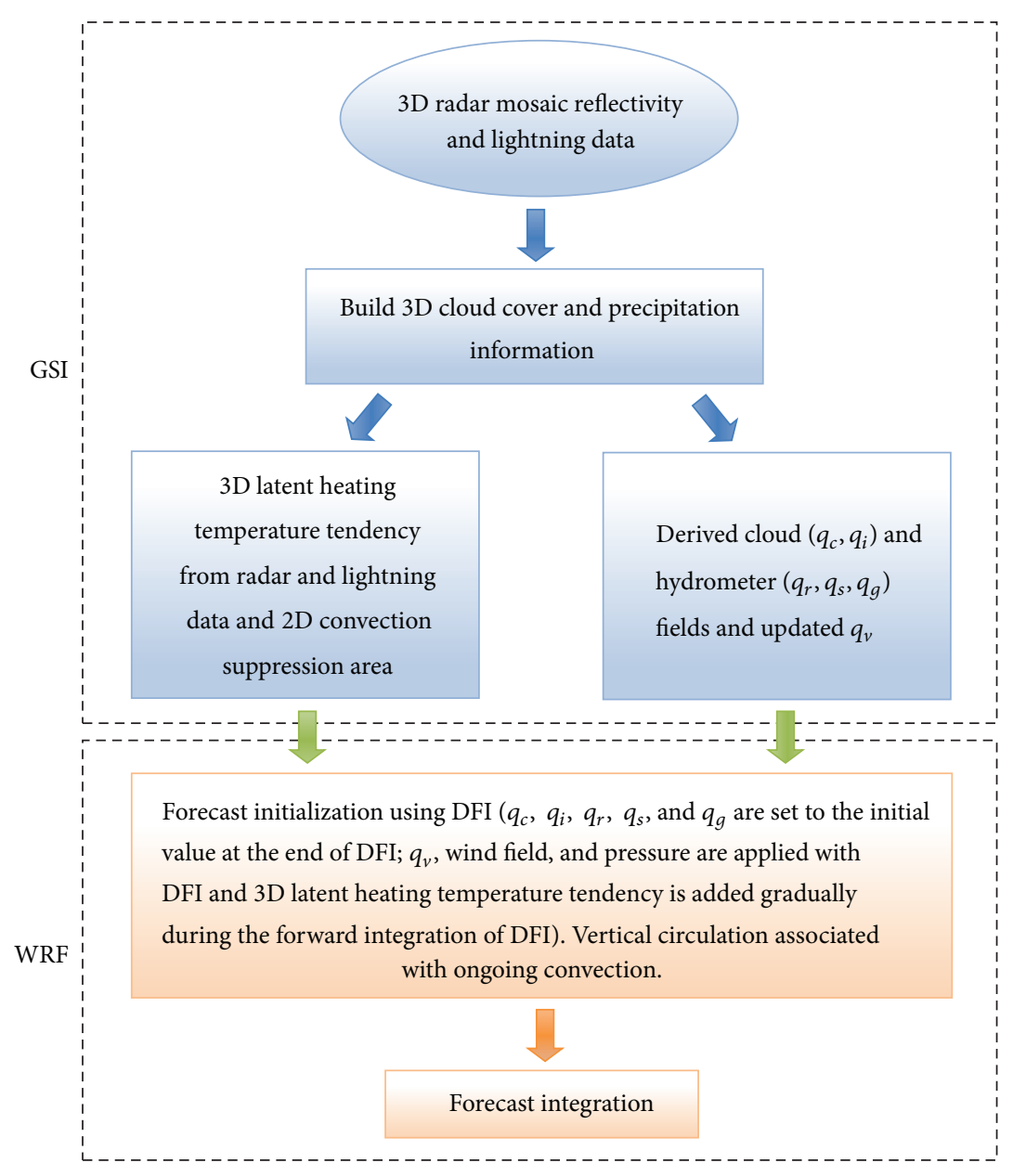

FIGURE 1: Flow chart of the radar-enhanced WRF-GSI system.

Satellite, Data, and Information Service) satellite cloud top products, surface METAR (meteorological terminal aviation routine) observations, lightning data, and radar reflectivity. Then, cloud and hydrometeor fields are updated in the cloud cover region. Additionally, 3D latent-heating based temperature tendencies are calculated from radar/lightningproxy reflectivity, and convection areas are identified where the depth of the cloud cover is greater than $300 \mathrm{hPa}$. These two fields, including the derived latent-heating based temperature tendency and the "no-echo" array, are passed to the WRFARW model and are digitally filtered before the forecast is run. A flow chart for this procedure is shown in Figure 1.

2.1. Determining the 3D Volumetric Cloud Fraction. Most of the retrieving calculations and adjustments within the cloud analysis procedure are applied in the cloud cover region. In the GSI system, this cloud cover information is represented by a $3 \mathrm{D}$ volumetric cloud fraction (VCF). Therefore, accurate determination of the VCF is extremely important. The GSI system uses the background field (the WRF forecast), together with surface METAR (weather, clouds, ceiling, and visibility) data, GOES single field cloud top products provided by NESDIS (pressure, temperature, and cloud fraction), and 3D radar reflectivity mosaic and lightning data to generate the 3D VCF, cloud type, and precipitation type information.

In the radar/lightning-proxy reflectivity data process, if none of the above indicates that cloud is present, then the height of the cloud base is set to the lifting condensation level. Otherwise, the cloud base is set to the lowest level where the cloud fraction is larger than 0.2. For layers above the cloud base and with grid reflectivity larger than a certain threshold ( $>15 \mathrm{dBZ}$, below $2000 \mathrm{~m}$; >10 dBZ, above $2000 \mathrm{~m}$ ), the VCF is set to 1 . Radar/lightning-proxy reflectivity provides the mid-troposphere information missed by surface and satellite observations, as well as giving a more accurate location for the cloud cover.

2.2. Temperature Tendency and Convection Suppression. After constructing the $3 \mathrm{D} \mathrm{VCF}$, the latent-heating based temperature tendency field, $T_{\text {ten }}$, is calculated from the gridded radar/lightning-proxy reflectivity in the cloud cover region according to

$$
T_{\text {ten }}=\left(\frac{1000}{p}\right)^{R_{d} / c_{p d}} \frac{\left(L_{v}+L_{f}\right) Q_{s}}{n \cdot c_{p d}},
$$


where $R_{d}$ is the specific gas constant for dry air, $c_{p d}$ is the specific heat of dry air at constant pressure, $L_{v}$ is the latent heat of vaporization at $0^{\circ} \mathrm{C}, L_{f}$ is the latent heat of fusion at $0^{\circ} \mathrm{C}, n$ is the number of forward integration steps of DFI, and

$$
Q_{s}=1.5 \times \frac{10^{z / 17.8}}{264083}
$$

in which $z$ is the grid radar/lightning-proxy reflectivity. The upper limit of the temperature tendency is set to $0.4^{\circ} \mathrm{C}$. The latent-heating based temperature tendency generated from reflectivity is regarded as an observation and used to replace the temperature tendency obtained from the cumulus parameterization and the explicit microphysics scheme in the forward integration unit of the DFI.

Areas of convection can only be identified if the vertical depth of the radar coverage is larger than $300 \mathrm{hPa}$. The maximum value of the temperature tendency in a column has to exceed $0.0002 \mathrm{~K} / \mathrm{s}$ for the area to be considered a convection area. Otherwise, a no-convection area is determined and the CAPE (convective available potential energy) depth in the convection scheme is set to a near-zero value, effectively suppressing convection during DFI forward integration. Where the vertical depth of radar coverage is insufficient, the area remains unclassified.

2.3. Cloud Liquid Water/Ice Algorithm. Saturation water and ice vapor pressure are calculated using (3) and (4) below. Then, the water vapor mixing ratio $q_{v w}$ and the ice vapor mixing ratio $q_{v i}$ in saturated conditions are calculated using (5). Next, the moisture vapor mixing ratio $q_{v s}$ in saturation status at any temperature is calculated using (6) and (7):

$$
\begin{aligned}
& e_{s w}=6.1121 \times \exp \left(\frac{17.67 \times(T-273.15)}{T-29.65}\right), \\
& e_{s i}=6.1121 \times \exp \left(22.514-\frac{6150}{T}\right), \\
& q_{v}=\varepsilon \frac{e_{s}}{p-e_{s}}, \\
& q_{v s}=\text { weight } \times q_{v w}+(1-\text { weight }) \times q_{v i},
\end{aligned}
$$

where

$$
\text { weight }= \begin{cases}1, & T>263.15 \\ \frac{T-233.15}{263.15-233.15}, & 233.15 \leq T \leq 263.15 \\ 0, & T<233.15\end{cases}
$$

In (5) $e_{s}$ is either $e_{s w}$ or $e_{s i}$, and $\varepsilon \approx 0.622$ is the ratio of the molecular weight of water vapor to dry air. The cloud liquid content $q_{\text {clc }}$ is $5 \%$ of the value of the vapor mixing ratio $q_{v s}$, with a minimum value of $0.0001 \mathrm{~g} / \mathrm{kg}$. Cloud water and cloud ice are calculated using (8) and (9) as follows:

$$
\begin{aligned}
& q_{c}=\text { weight } \times q_{\mathrm{clc}}, \\
& q_{i}=(1.0-\text { weight }) \times q_{\mathrm{clc}} .
\end{aligned}
$$

2.4. Rain, Snow, and Hail Adjustment. Before retrieving hydrometeors from the radar/lightning-proxy reflectivity, precipitation types were first classified using the grid radar/ lightning-proxy reflectivity (GREF) and the wet-bulb temperature $\left(T_{w}\right)$. In the GSI system, precipitation is categorized into six types: "No rain," if GREF is below $0 \mathrm{dBZ}$; "rain," if $T_{w} \geqslant 1.3^{\circ} \mathrm{C}$; if $0.0^{\circ} \mathrm{C} \leqslant T_{w} \leqslant 1.3^{\circ} \mathrm{C}$, then the precipitation is assigned the same type as at the nearest higher model level; if $T_{w}$ is below $0.0^{\circ} \mathrm{C}$, then precipitation is defined as "snow," "freezing rain," or "sleet," depending on the nearest higherlevel precipitation type; the precipitation type is further upgraded to "hail" when the GREF is larger than $50 \mathrm{dBZ}$. Once the precipitation type has been defined, the $3 \mathrm{D}$ mixing ratios of rain, snow, and hail are retrieved from the reflectivity employing the Thompson et al. [31], Ferrier [32], and Ferrier et al. [33], or Kessler [34] approach when the grid reflectivity is greater than $10 \mathrm{dBZ}$.

2.5. Digital Filter Initialization in the WRF Model. Additional changes were made to the WRF-DFI model. The 3D latent heat calculated from the radar reflectivity and lightning data during the GSI process is averaged and then read in during the DFI forward integration to replace the model latent heating rate derived from both explicit and parameterized precipitation schemes. This replacement may lead to dynamic and thermal responses consistent with convection-associated latent heating. Furthermore, convection is inhibited over the "no-echo" area where radar/lightning-proxy reflectivity shows an absence of convection. In the official WRF-DFI model, all variables, including the wind fields, temperature, pressure, and moisture fields, undergo digital filtering in the DDFI forward and backward integration. However, in the modified framework used here, the hydrometeors (cloud liquid water/ice, rain, snow, and hail), but not the vapor mixing ratio, were all set to the initial value at the end of the backward (integrating the adiabatic, reversible terms in the equations only) and forward (using full physics and mixing/dissipation terms) integration.

\section{Data and Experimental Design}

Lightning, strong wind, hail, and rainstorms occurred in most regions of Anhui Province from the afternoon until midnight on June 5, 2009. This convective weather system led to serious economic losses and casualties. The Department of Civil Affairs reported that 4.82 million people were affected by the storm, with 25 people killed, 3 people lost, and 215 people injured; the total area of crops destroyed was $205.4 \mathrm{~km}^{2}$. This convective weather system influenced a broad region that included most of Anhui Province, the western part of Jiangsu Province, and the Jiujiang area of Jiangxi Province. The development of this convective weather system is shown in Figure 2(c) and the first column in Figure 6. At 0600 UTC, the convective system lies over the central part of Jiangsu Province. Over the next few hours, the region of high radar reflectivity became larger and the convective system moved gradually towards Anhui Province, before sweeping across almost the whole of this province. In this study, this 
convective case was analyzed by assimilating radar reflectivity data from Hefei and cloud-to-ground lightning data for Anhui Province.

The Doppler radar at Hefei $\left(117.716^{\circ} \mathrm{E}, 31.883^{\circ} \mathrm{N}\right)$ in China is a $10 \mathrm{~cm}$ wavelength Doppler radar with a $1^{\circ}$ half-power beam width. The data consist of volume scans of radar reflectivity, radial velocity, and spectrum width collected in volume scan mode during the period of precipitation, with the elevation angle increasing in steps from $0.5^{\circ}$ to $19.5^{\circ}$. The number of elevation angle steps and the temporal resolution of the data depend on the operational mode of the radar. Accordingly, reflectivity values are recorded at $1 \mathrm{~km}$ intervals along the radar beam, whereas velocity parameters are recorded at $250 \mathrm{~m}$ intervals. Each volume scan takes approximately five minutes. The lightning flash data used in this study were obtained from the lightning location network of Anhui Province, which consists of 11 lightning location systems in Fuyang, Chuzhou, Liuan, Anqing, Huangshan, Xuancheng, Bengbu, Huaibei, Tongling, Haozhou, and Hefei. This network is primarily used to detect cloud-to-ground flashes and can differentiate the polarity of flashes.

The lightning flash data were transformed into 3D proxy radar reflectivity based on a simple assumed relationship between flash density within a given RUC grid $(13.545087 \mathrm{~km})$ and the corresponding column maximum of grid-averaged reflectivity in the GSI code:

$$
\mathrm{REFL}=\min [40,15+2.5 \times \mathrm{LTG}] .
$$

REFL is the derived proxy column maximum of reflectivity and LTG is the lightning flash number in a given RUC grid box summed over a 40-minute period around the analysis hour ( -30 to +10 minutes). This statistical relationship between lightning flashes per grid column and column maximum reflectivity is complemented by a set of statistical relationships between the column maximum reflectivity and the vertical reflectivity profile. The vertical profile of reflectivity is a function of the column maximum reflectivity. The vertical profile varies as column maximum reflectivity increases (in $5 \mathrm{dBZ}$ bins) from $20-25 \mathrm{dBZ}$ to $45-50 \mathrm{dBZ}$. Thus, the lightning flash rate can first be mapped to a column maximum proxy reflectivity then to a vertical distribution of proxy reflectivity.

The correlation coefficient between proxy reflectivity and observed radar reflectivity from 0600 to 0900 UTC was 0.847 , and the root mean square error (RMSE) was 6.062 . Figure 2(a) shows the observed lightning strikes counted on a grid between 0530 and 0610 UTC. Warmer colors represent higher numbers of lightning strikes. It is clear that there were more lightning strikes in the middle of Jiangsu Province and east of Anhui Province. Figure 2(b) indicates the corresponding distribution of lightning-proxy composite reflectivity derived for 0600 UTC, while Figure 2(c) indicates the distribution of observed composite reflectivity. The lightningproxy composite reflectivity displays a similar pattern to the observed composite reflectivity and the high proxy composite reflectivity (higher than $30 \mathrm{dBZ}$ ) follows the same pattern as the distribution of high numbers of lightning strikes. Overall, the lightning-proxy composite reflectivity generated from the lightning location network data had a similar pattern to the observed radar composite reflectivity; however, the intensity and extent were lower than for the radar, because the lightning did not occur everywhere within the region of high radar reflectivity.

To study the effect of lightning data on the forecast of this convective weather system using the radar-enhanced WRF-GSI system, two assimilation experiments were performed. Both experiments used NCEP (National Centers for Environmental Prediction) FNL (Final) Operational Global Analysis as background and lateral boundary conditions, and the initial forecasts started at 0000 UTC, June 5, 2009, and ran for $6 \mathrm{~h}$. Exp. lghtn assimilated lightning data from Anhui Province at hourly intervals between 0600 and 0900 UTC, followed by a $6 \mathrm{~h}$ WRF model forecast. Exp. radar assimilated the Hefei radar reflectivity data at hourly intervals from 0600 to 0900 UTC, followed by a $6 \mathrm{~h}$ WRF model forecast. In this study, the complex cloud analysis package in the radarenhanced GSI system was used to assimilate radar/lightningproxy reflectivity. All these forecasts were compared with a baseline control forecast (Exp. CTL) that started directly from the NCEP FNL analysis at 0000 UTC.

All experiments were performed on a domain centered at the Hefei radar, with a horizontal spacing of $13.545 \mathrm{~km}$. The model network was composed of $101 \times 101 \times 50$ grid points. The pressure at the top of the model was set to $10 \mathrm{hPa}$, and the time step for integration was $60 \mathrm{~s}$. The main model physics included the Lin et al. scheme [35], the RRTM scheme [36], the Goddard short wave scheme [37], the Monin-Obukhov (Janjić) scheme [38, 39], the RUC land-surface model scheme [40], the Mellor-Yamada-Janjić TKE scheme [38], and the Grell 3D ensemble scheme [41].

\section{Analysis and Results}

4.1. Assimilation Results. To analyze the effect of assimilating lightning data in this mesoscale convective system case, we focused on Exp. lghtn from the radar-enhanced WRF-GSI system. Figure 3 shows the analyzed maximum reflectivity from Exp. CTL, lghtn, and radar at the first assimilation time (0600 UTC). Compared with the observations in Figure 2(c), Exp. CTL did not correctly forecast the corresponding reflectivity, whereas the forecast maximum reflectivity values in Exp. lghtn and in Exp. radar were similar to those observed. This shows that assimilating the lightning and radar data to adjust the microphysical cloud variables can cause the forecast reflectivity to quickly approach the observations. The region and intensity of the analyzed maximum reflectivity in Exp. lghtn were smaller than the values in Exp. radar, which were similar to the lightning-proxy composite reflectivity.

The first column of Figure 4 shows the lightning-proxy reflectivity and observed radar reflectivity at the 18th level and the horizontal increments of the perturbation potential temperature, water vapor mixing ratio, rain water mixing ratio, and snow mixing ratio, ice mixing ratio, and cloud water mixing ratio in Exp. lghtn, and the second column shows these quantities for Exp. radar. All of the horizontal increments had patterns similar to the lightning-proxy 


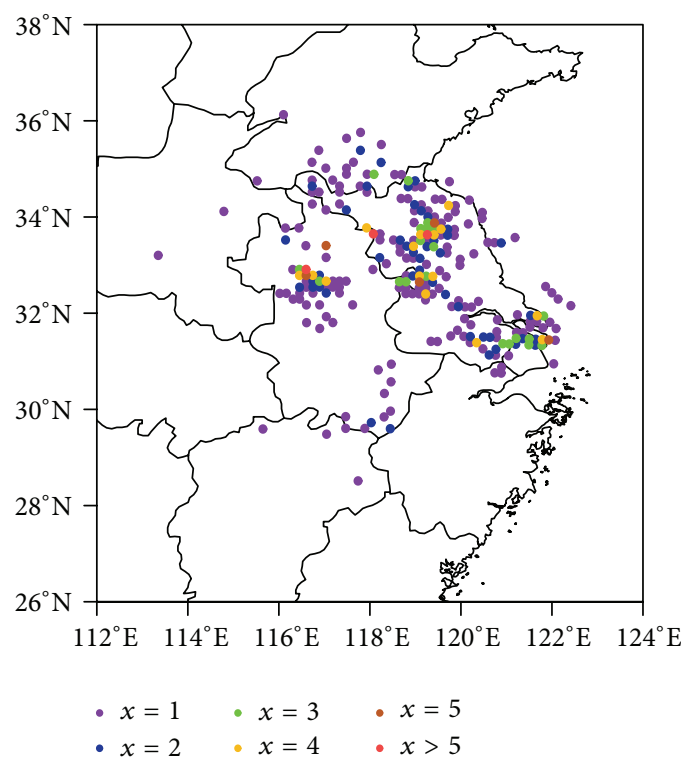

(a)

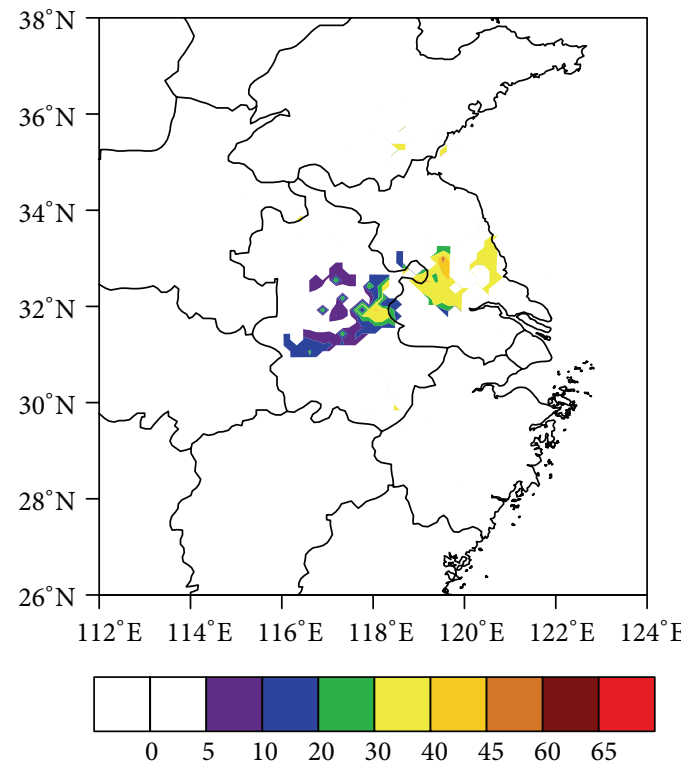

(b)

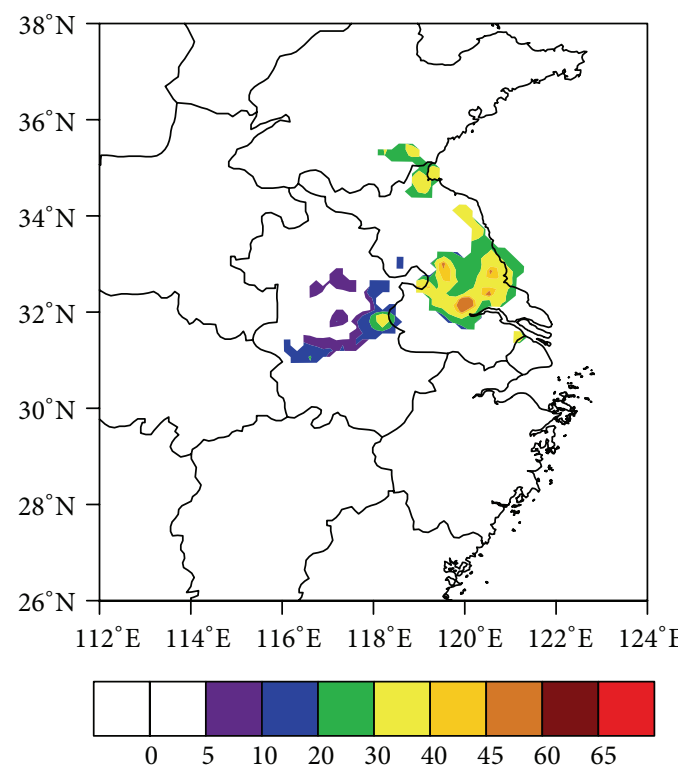

(c)

Figure 2: Comparison of (a) cloud-to-ground lightning strikes counted on a grid from 0530 to 0610 UTC, (b) lightning-proxy composite reflectivity (dBZ), and (c) observed composite reflectivity (dBZ) at 0600 UTC.

reflectivity and observed radar reflectivity; however, the area of the increments differed. In Exp. lghtn, the maximum horizontal increment of perturbation potential temperature was $2.4 \mathrm{~K}$ and was in the region where the lightning-proxy reflectivity was higher than $30 \mathrm{dBZ}$. The maximum horizontal increment of water vapor mixing ratio was $2.5 \mathrm{~g} / \mathrm{kg}$. The areas of the horizontal increments of rain mixing ratio and of snow mixing ratio were relatively small, and the maximum increment values were 1.5 and $1.8 \mathrm{~g} / \mathrm{kg}$, for Exp. lghtn and Exp. radar, respectively. The maximum increments of ice mixing ratio and of cloud water mixing ratio were low $(0.02$ and $0.08 \mathrm{~g} / \mathrm{kg}$, resp.) at $0600 \mathrm{UTC}$, which indicated that the adjustment of the ice mixing ratio and cloud water mixing ratio at 0600 UTC in the radar-enhanced WRF-GSI system was not obvious after assimilating lightning data. However, in Exp. radar, all horizontal increments were higher, and all incremental regions were larger than for Exp. lghtn. The maximum horizontal increment of the perturbation potential temperature was $3.6 \mathrm{~K}$, while the maximum horizontal increments of the water vapor mixing ratio, rain mixing ratio, snow mixing ratio, ice mixing ratio, and cloud water mixing ratio were $3.0,3.5,4.2,0.025$, and $0.08 \mathrm{~g} / \mathrm{kg}$, respectively. 

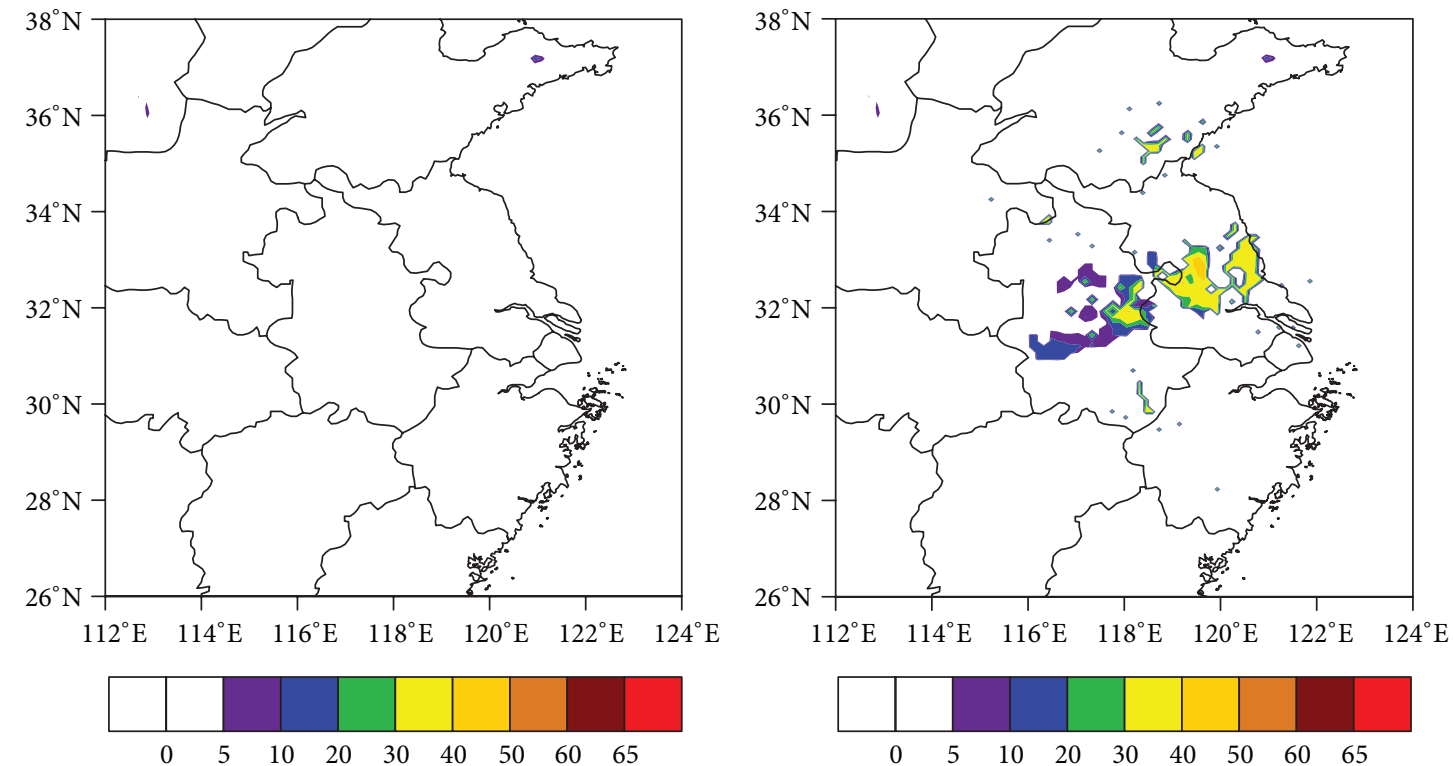

(a)

(b)
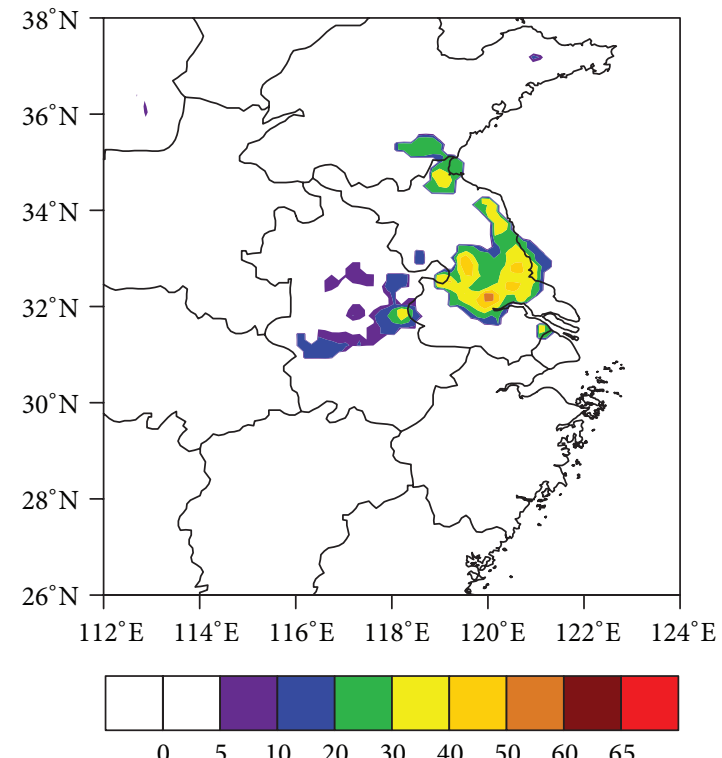

(c)

Figure 3: Analyzed maximum reflectivity (dBz) in (a) Exp. CTL, (b) Exp. lghtn, and (c) Exp. radar at 0600 UTC.

The last two columns of Figure 4 illustrate cross sections of the distribution of vertical lightning-proxy reflectivity, observed radar reflectivity, and the vertical increment of the perturbation potential temperature, water vapor mixing ratio, rain water mixing ratio, snow mixing ratio, ice mixing ratio, and cloud water mixing ratio of Exp. lghtn and Exp. radar along $32.89^{\circ} \mathrm{N}$ at $0600 \mathrm{UTC}$. The red line indicates the $0^{\circ} \mathrm{C}$ temperature line. In Exp. lghtn, the high radar reflectivity is clearly located at lower levels, particularly below $6.6 \mathrm{~km}$. The highest value of lightning-proxy reflectivity was $44 \mathrm{dBZ}$. However, the observed radar reflectivity value is higher and spread over a wider range of levels. As shown in Figure 4(b3), the maximum vertical increment of perturbation potential temperature was $4.2 \mathrm{~K}$ and occurred at a height of approximately $3 \mathrm{~km}$. The maximum vertical increments of the water vapor mixing ratio and rain water mixing ratio were 8.4 and $1.3 \mathrm{~g} / \mathrm{kg}$, respectively. The vertical increments of the snow mixing ratio and ice mixing ratio were primarily above the $0^{\circ} \mathrm{C}$ temperature line, and the maximum values were 1.8 and $0.055 \mathrm{~g} / \mathrm{kg}$, respectively. The maximum vertical increment of the cloud water mixing ratio was $0.096 \mathrm{~g} / \mathrm{kg}$. In Exp. radar, the vertical reflectivity was stronger than that in Exp. lghtn, and the higher-value region was larger. The maximum vertical increment of perturbation potential temperature was $4.2 \mathrm{~K}$, 


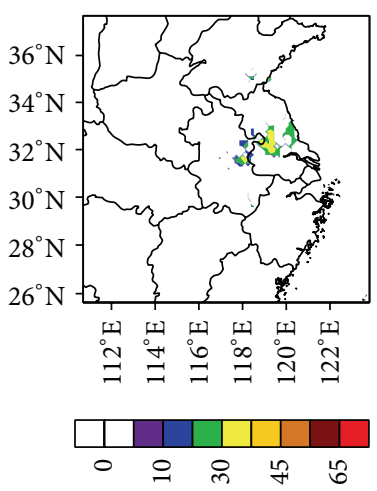

(a1)

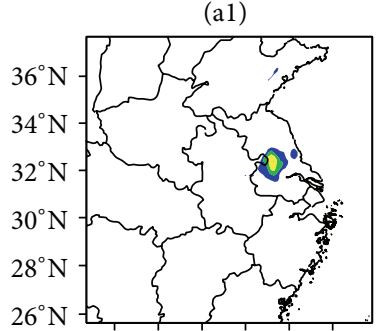

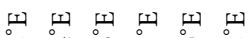

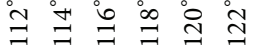

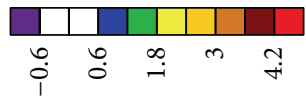

(b1)

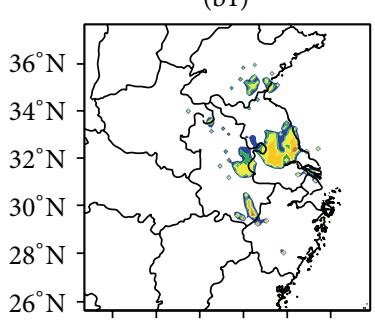

더 떠 떠 띠 뙤 띠

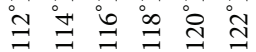

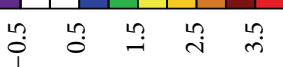

(c1)

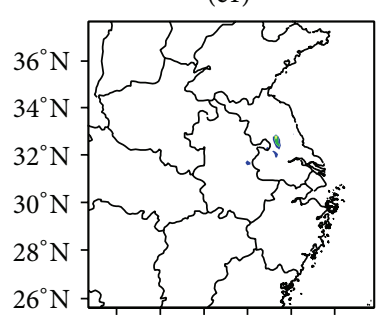

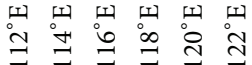

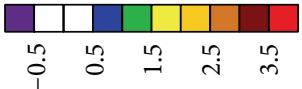

(d1)

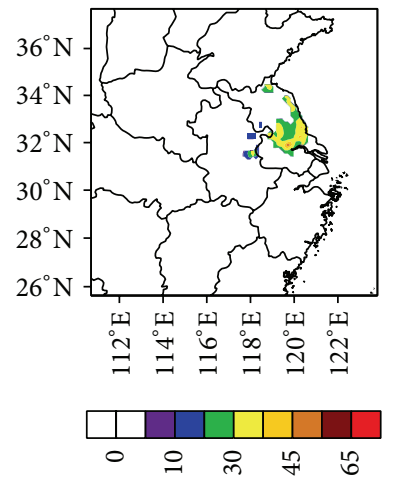

(a2)

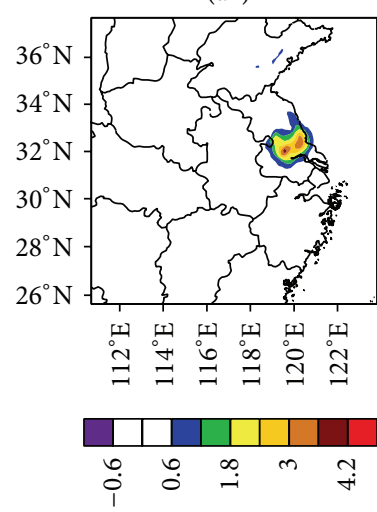

(b2)

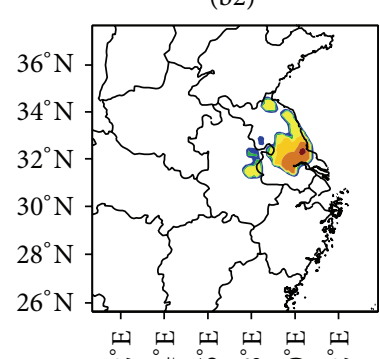

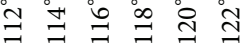

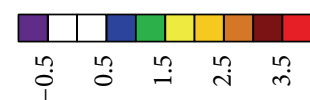

(c2)

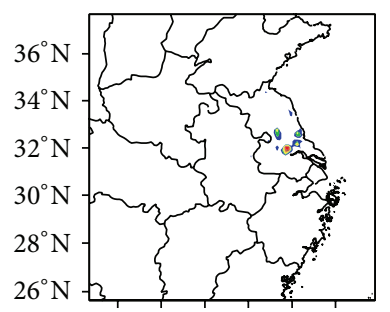

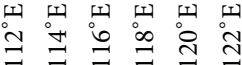

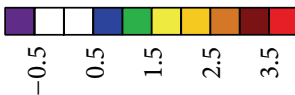

(d2)
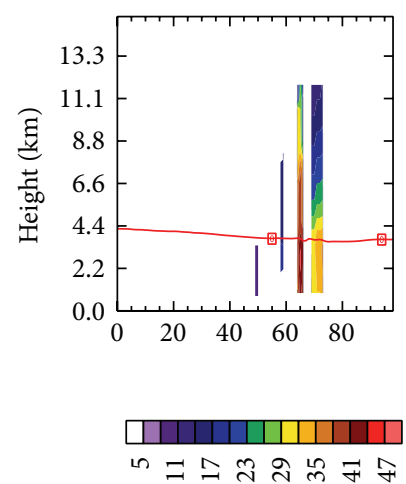

(a3)

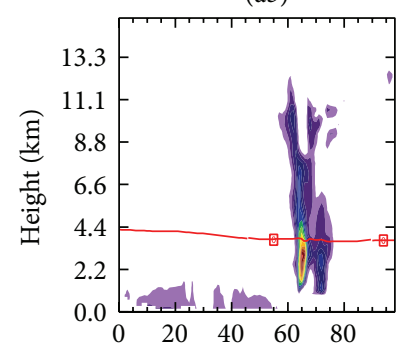

पामापा|ा|ा|ा|ा|ा

ڤै

(b3)
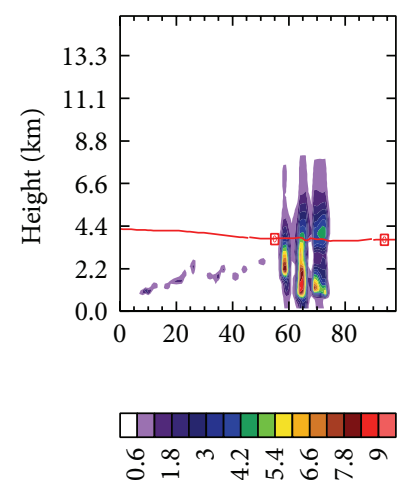

(c3)

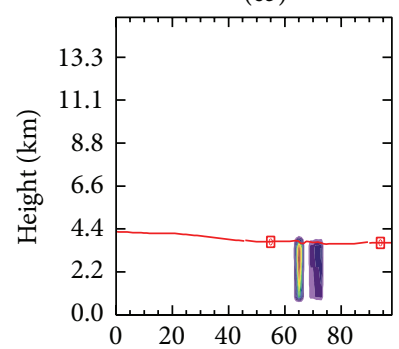

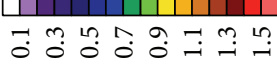

(d3)

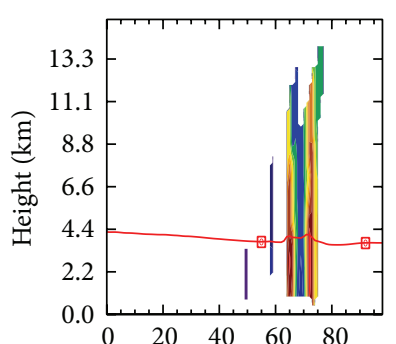

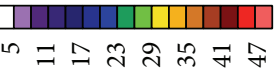

(a4)

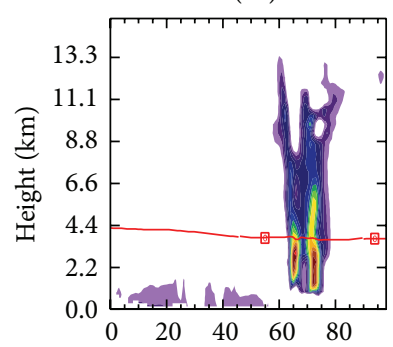

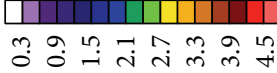

(b4)
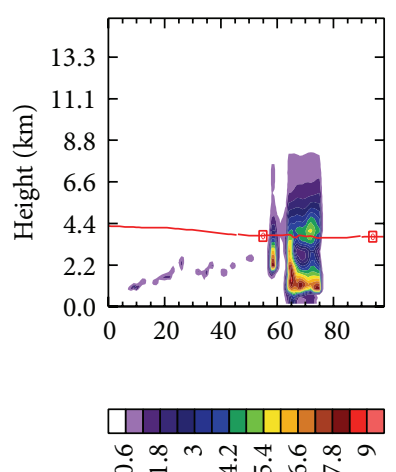

(c4)

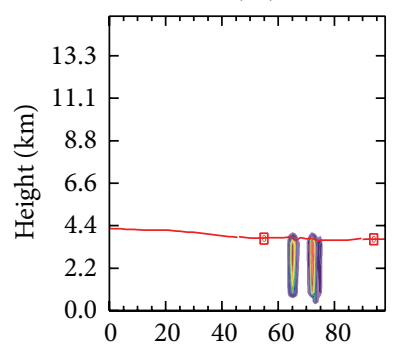

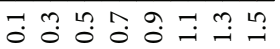

(d4)

FIgUre 4: Continued. 


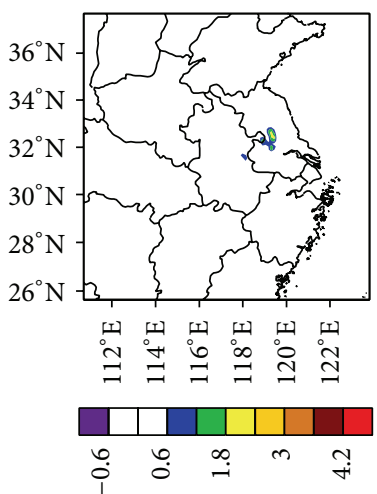

(e1)

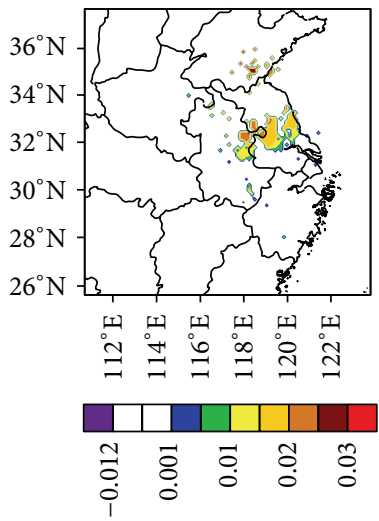

(f1)

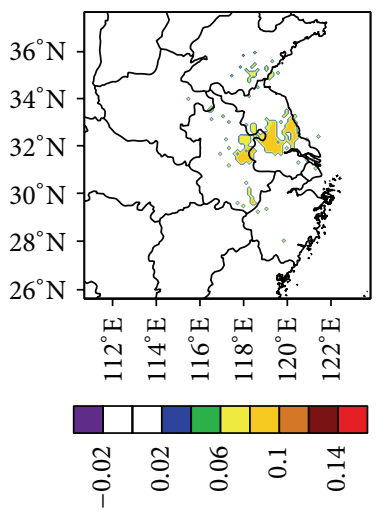

(g1)

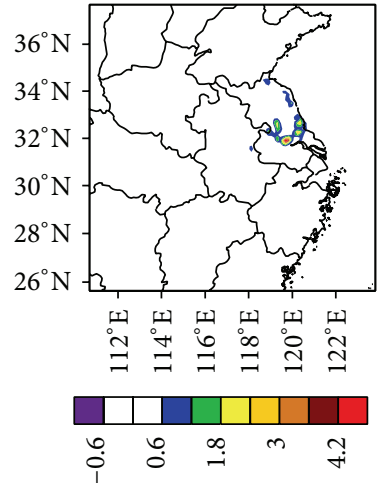

(e2)

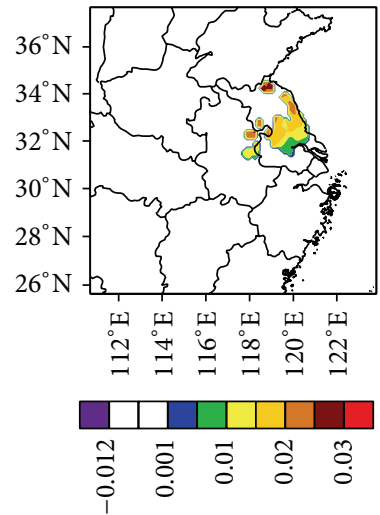

(f2)

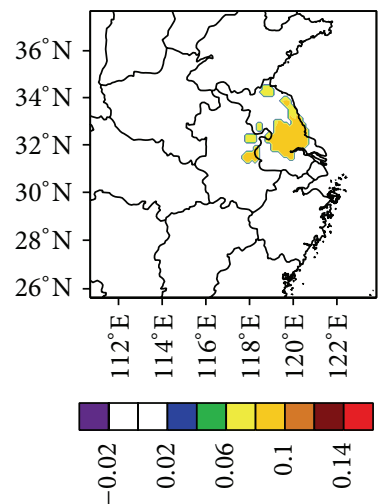

(g2)
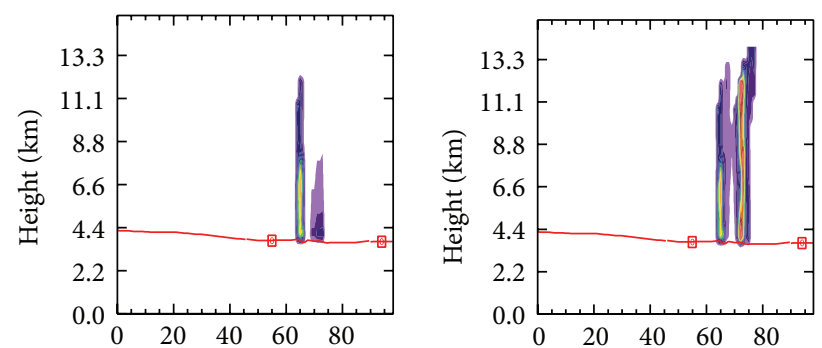

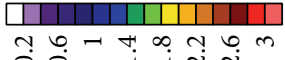

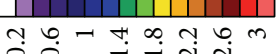

(e3)

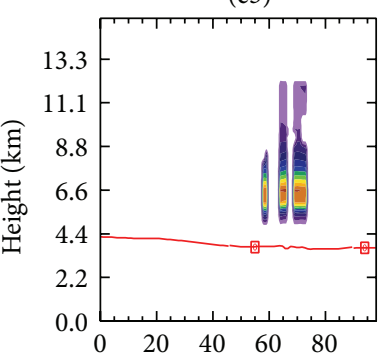

(e4)

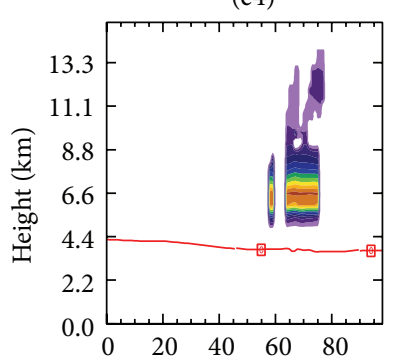

पपापापापापाप

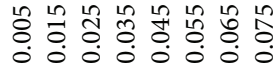

(f3)

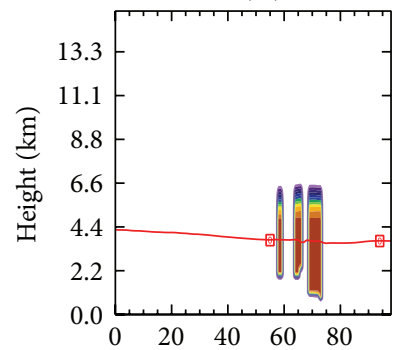

(f4)
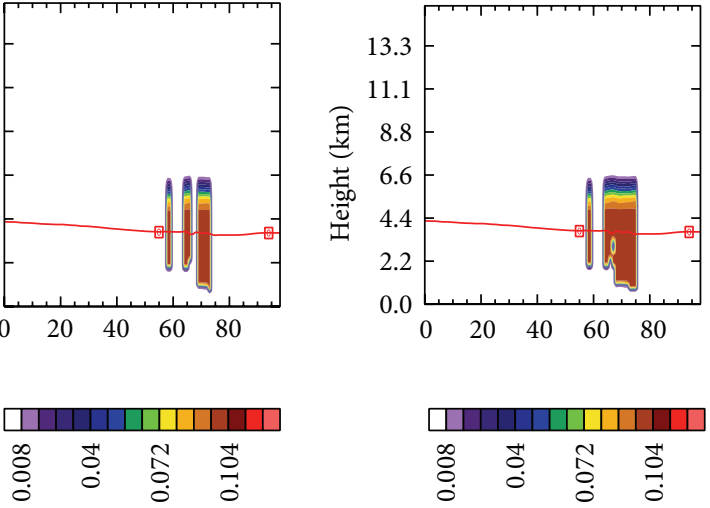

(g3)

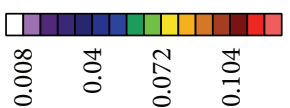

(g4)

FIGURE 4: The distributions of horizontal and vertical increments for experiments lghtn and radar at 0600 UTC. The first two columns are horizontal increments and the last two columns are vertical increments along $32.89^{\circ} \mathrm{N}$. (al) is the lightning-proxy reflectivity at the 18 th level and (a2) is the observed radar reflectivity at the 18th level (unit: dBZ). (a3) is the vertical distribution of lightning-proxy reflectivity, and (a4) is the observed radar reflectivity. Rows two to seven are the increments of perturbation potential temperature (unit: K), water vapor mixing ratio, rain water mixing ratio, snow mixing ratio, ice mixing ratio, and cloud water mixing ratio, respectively (unit: $\mathrm{g} / \mathrm{kg}$ ).

while the those for the water vapor mixing ratio, rain mixing ratio, snow mixing ratio, ice mixing ratio, and cloud water mixing ratio were $8.4,1.5,3,0.06$, and $0.096 \mathrm{~g} / \mathrm{kg}$, respectively. Although some values of the vertical increments were similar to those in Exp. lghtn, the regions with vertical increments were more extensive than those regions of Exp. lghtn. In general, all of the horizontal and vertical increments in Figure 5 occurred at reasonable locations, and the values were positive and substantial suggesting that assimilation in the radar-enhanced WRF-GSI system performed a satisfactory adjustment. All of the increments in Exp. radar were larger than those in Exp. lghtn, particularly for the perturbation potential temperature and water vapor mixing ratio, and this was due to the better assimilation of observations of both intensity and area in Exp. radar.

4.2. Forecast Results. To compare the effect of assimilating lightning data at different times on the forecasts, Exp. 
lghtn was divided into four separate experiments: da_1, da_2, da_3, and da_4. Experiment da_1 assimilated lightning data at 0600 UTC using the forecast field from Exp. CTL at 0600 UTC as a first guess field. Experiment da_2 also assimilated lightning data at 0700 UTC based on Exp. da_1. Similarly, da_3 and da_4 also assimilated lightning data at 0800 UTC and at 0900 UTC, respectively. Equitable threat scores (ETS) [42] at five thresholds (10, 15, 20, 25, and $30 \mathrm{dBZ})$ were used to provide a quantitative comparison of the forecast composite reflectivity of these five experiments (the four separate experiments and Exp. CTL) with the observed radar reflectivity (Figure 5). The ETS of Exp. CTL at low thresholds was small $(<0.10)$, while, at high thresholds $(>15 \mathrm{dBZ})$, the ETS values of Exp. CTL approached zero. After assimilating lightning data, the ETS values rose quickly with a value of 0.45 at the $10 \mathrm{dBZ}$ threshold, and at $30 \mathrm{dBZ}$ the value was still 0.34 . The results of cycled assimilation were notable, with the best value of ETS for Exp. da_4. At 0900 UTC, the ETS values of Exp. da_4 were $0.37,0.37,0.53,0.40$, and 0.27 . Generally, the improvement in da_4 was significant at both low and high thresholds and persisted for more than $7 \mathrm{~h}$.

The behavior of the forecast composite reflectivity can be seen more clearly in Figure 6, which shows hourly forecasts together with the observed radar reflectivity from 0900 to 1500 UTC. The first column is the observed radar reflectivity, and columns two to four show the forecast composite reflectivity of Exp. CTL, Exp. lghtn, and Exp. radar, respectively. In Exp. CTL, the forecast composite reflectivity was almost zero in high reflectivity regions, whereas, after four cycles of lightning data assimilation, the forecast composite reflectivity quickly approached the observations, and the forecast patterns were similar to the observed pattern, particularly in Exp. lghtn. During the first 2 h, Exp. lghtn and Exp. radar obviously overestimated some high reflectivity regions, but Exp. lghtn performed better than Exp. radar.

After a few hours, this overestimation was less clear, although the location of the forecast region of composite reflectivity moved away from its observed location. Nevertheless, the maintained forecast composite reflectivity was perfect after assimilation and could last for more than $6 \mathrm{~h}$, which indicated that the weakening of reflectivity was not clear due to a correct coordination between variables in the radar-enhanced WRF-GSI system after assimilation.

Figure 7 shows the ETS of forecast composite reflectivity for Exp. CTL, Exp. lghtn, and Exp. radar at different thresholds. The ETS values of Exp. CTL remained low at low thresholds and were almost zero at high thresholds. After cycling assimilation, the ETS values of Exp. lghtn and Exp. radar at every threshold improved substantially, and this significant improvement could last for more than $6 \mathrm{~h}$. At lower thresholds (10, 15, and $20 \mathrm{dBZ})$, the ETS values of Exp. radar were higher than those of Exp. lghtn in the first $4 \mathrm{~h}$ because of better increments, as shown in Figure 4, whereas these values fell below those of Exp. lghtn in the last $2 \mathrm{~h}$. However, at high thresholds $(25,30$, and $35 \mathrm{dBZ})$, the ETS values of Exp. radar were higher than those of Exp. lghtn in the first $3 \mathrm{~h}$ but then lower in the last $3 \mathrm{~h}$. The ETS values of Exp. radar rapidly decreased after several hours of forecasting, while the ETS values of Exp. lghtn slowly decreased after several hours of forecasting and even rose to higher values at high thresholds, as shown in Figures $8(\mathrm{~d}), 8(\mathrm{e})$, and 8(f). In general, the improvement in Exp. lghtn was more stable than that in Exp. radar because of a slower weakening of reflectivity. Usually, the improvement at low thresholds can be a reference for light rain forecasting, and the improvement at high thresholds can be a reference for rainstorms forecasting and can be used to follow the development of a convective system.

A better understanding of the effect on precipitation can be obtained by comparing the observed precipitation with the forecast 3 and $6 \mathrm{~h}$ precipitation from the three experiments (Figure 8). The first row shows the $3 \mathrm{~h}$ precipitation for the period 0900-1200 UTC, and the second row is for 1200-1500 UTC. The last row is the $6 \mathrm{~h}$ precipitation for $0900-1500$ UTC. The first column is the observed station precipitation, and columns two to four are the forecast precipitation of Exp. CTL, Exp. lghtn, and Exp. radar, respectively. From 0900 to 1200 UTC, heavy rain occurred over the northern part of Anhui Province and Zhejiang Province, as shown in the observations. In Exp. CTL, the heavy precipitation was not forecast. After assimilation, the high values of precipitation in Exp. lghtn and Exp. radar were clear, although there was a shift in the spatial location and an overestimate of the intensity. From 1200 to 1500 UTC, the observed precipitation moved to the southern part of Anhui and to the central part of Zhejiang provinces. In Exp. CTL, there was almost no precipitation forecast in Anhui Province, except in the central and eastern regions, and the precipitation forecast for Zhejiang Province was farther south than in the observations. Exp. lghtn and Exp. radar forecast high values of precipitation in the southern part of Anhui Province and in the northern and central parts of Zhejiang Province, although overestimates remained. From 0900 to 1500 UTC, heavy rain occurred in the northern, eastern, and southern parts of Anhui Province, and in the northern and central parts of Zhejiang Province; however, there was no heavy rain in Exp. CTL. The signals of heavy rain in Exp. lghtn and Exp. radar were clear and similar to the observations, although there was a shift in the spatial location and an overestimate. In the first $3 \mathrm{~h}$, the overestimation of precipitation in Exp. radar was larger than that in Exp. lghtn because the increments in assimilation in Exp. radar were higher, which led to a higher composite reflectivity after cycled assimilation and a stronger precipitation in the first $3 \mathrm{~h}$. Such discrepancies can also be seen in the results presented in Figures 6 and 8.

Figure 9 shows the quantitative analysis of forecast precipitation in these three experiments. There were two precipitation thresholds, $1 \mathrm{~mm}$ and $10 \mathrm{~mm}$, representing light rain and a rainstorm, respectively. At the light rain threshold, the threat scores of Exp. CTL over different time intervals were less than 0.40. The threat scores of Exp. lghtn and of Exp. radar were greatly improved, with values of approximately 0.70 , and with no discernible difference between the two experiments. However, at the rainstorm threshold, the Exp. lghtn result was obviously better than that of Exp. radar, and the threat scores of Exp. CTL were zero. The stronger adjustment in Exp. radar results in an overestimation of precipitation in the first few hours, and all ETS values of Exp. 


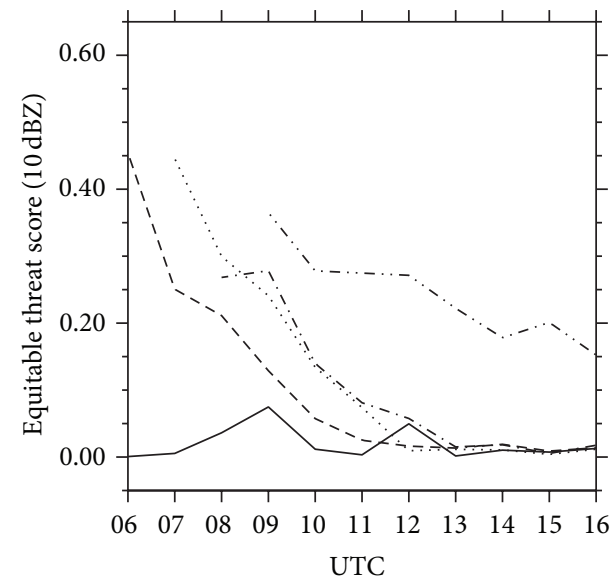

(a)

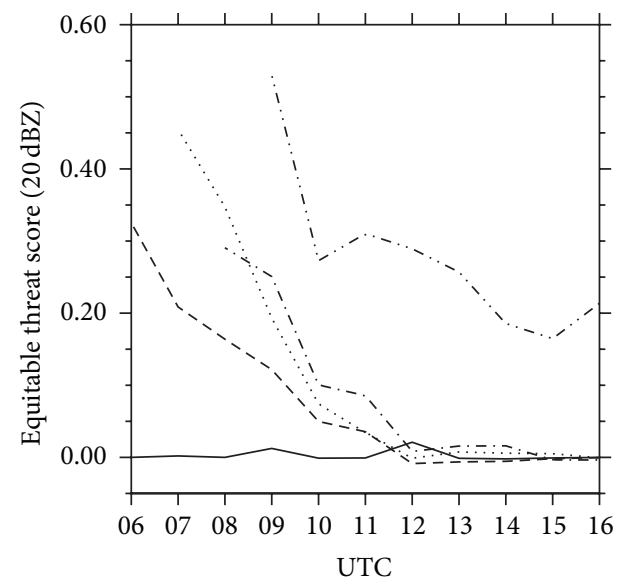

(c)

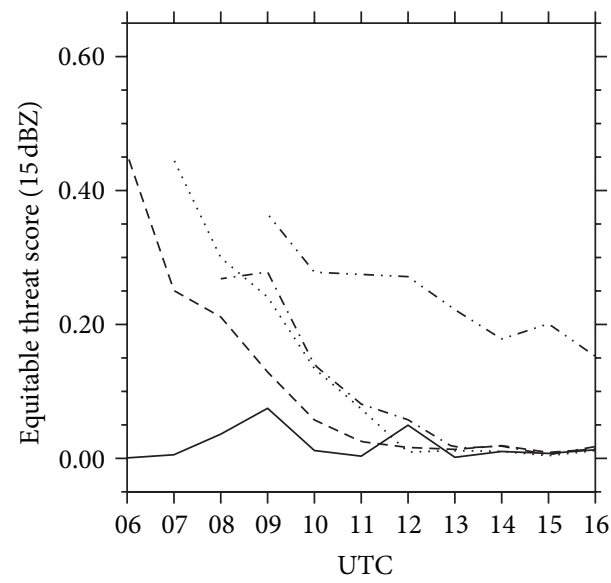

(b)

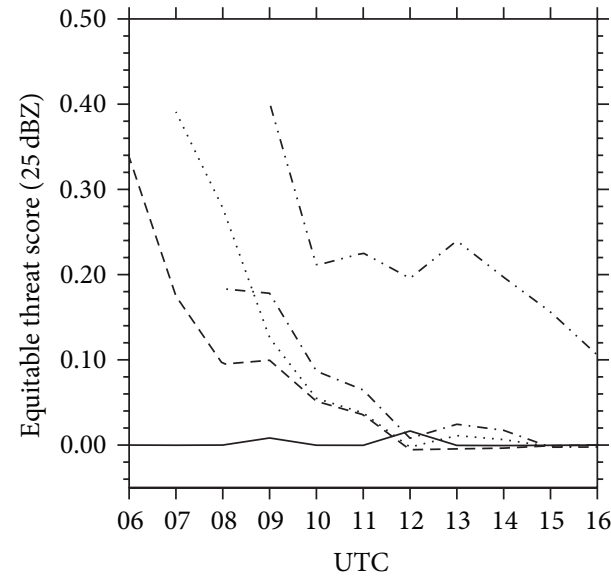

(d)

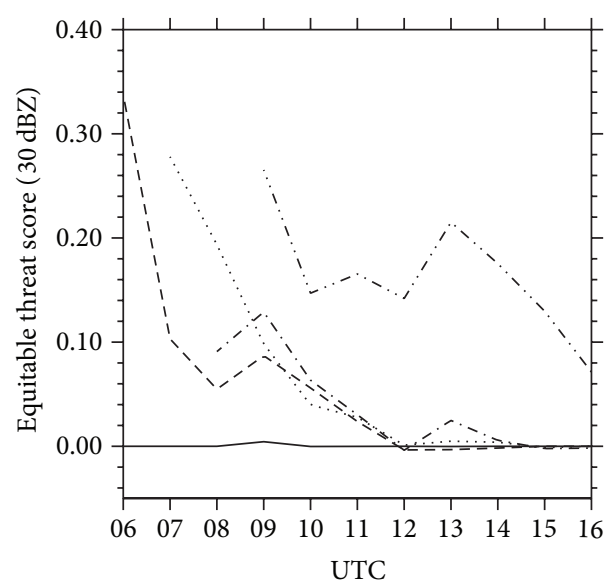

$$
\begin{array}{lll}
\ldots & \text { da_4 } 4 \quad-- & \text { da_1 } \\
\ldots & \text { da_3 } & \text { CTL } \\
\ldots . . & \text { da_2 }
\end{array}
$$

(e)

FIGURE 5: The ETS of the forecast composite reflectivity for the five experiments at (a) 10 , (b) 15 , (c) 20 , (d) 25 , and (e) $30 \mathrm{dBZ}$. 

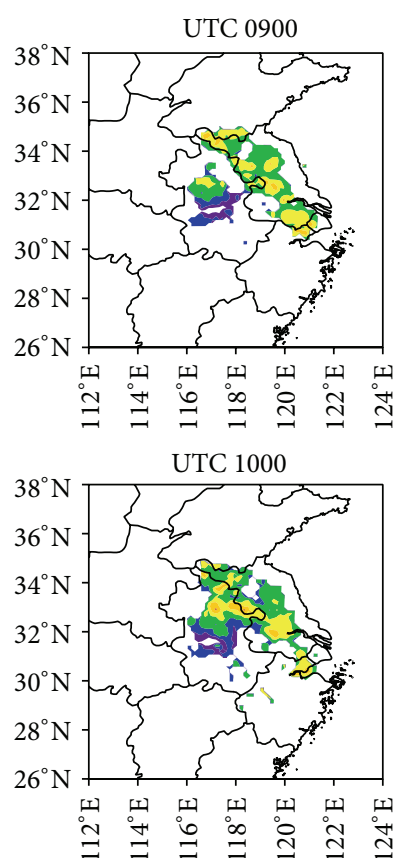

UTC 1100

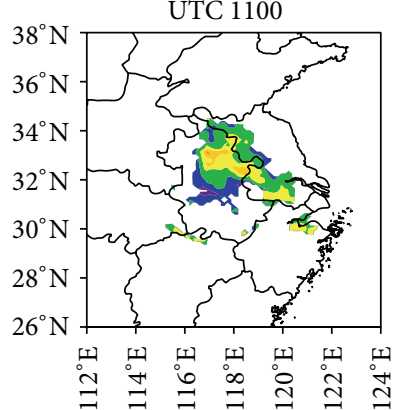

UTC 1200
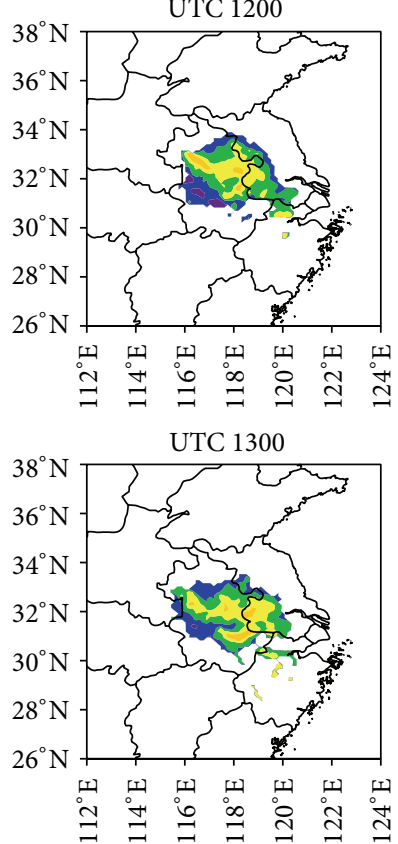

으으오이우융ㄴㄴ
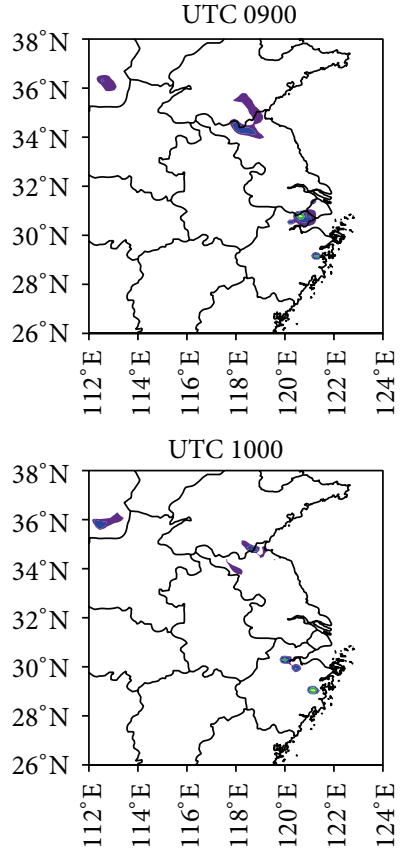

UTC 1100

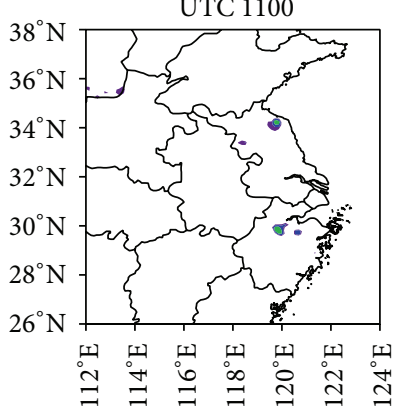

UTC 1200
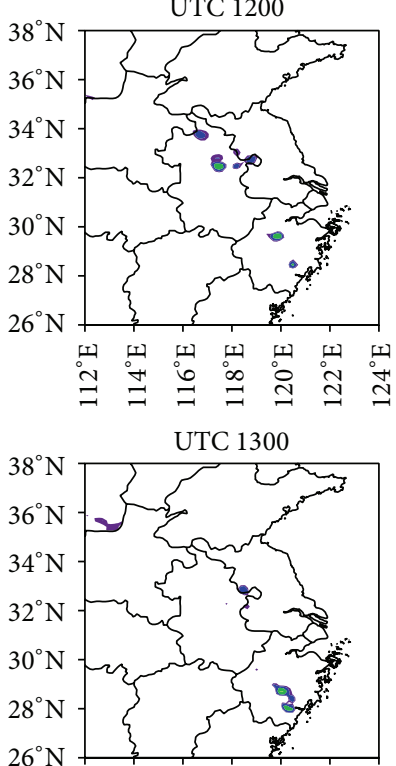

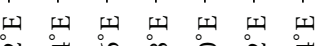

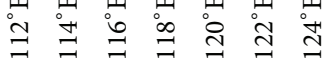

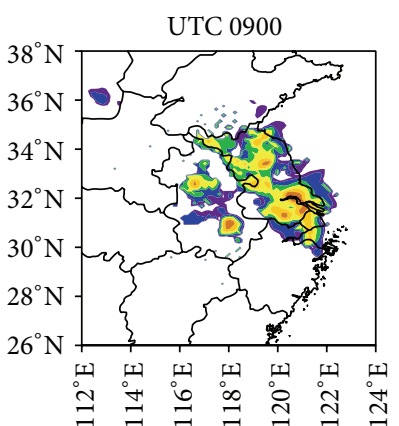

UTC 1000

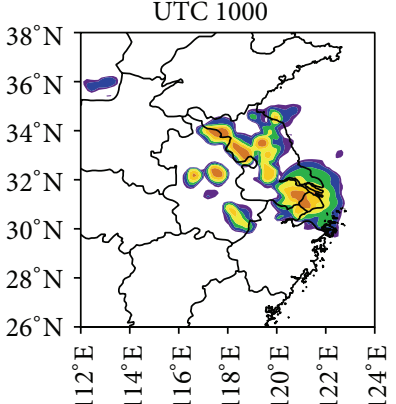

UTC 1100

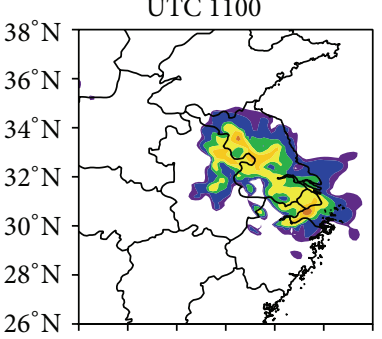

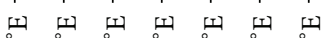

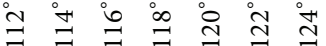

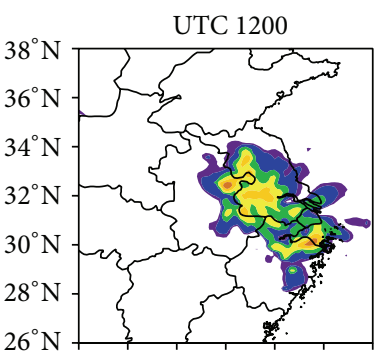

푀 뙤 떠 떠 뙤

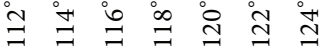

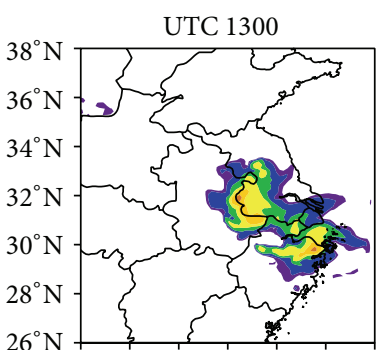

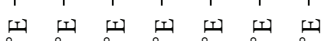

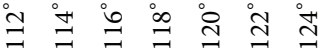

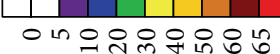

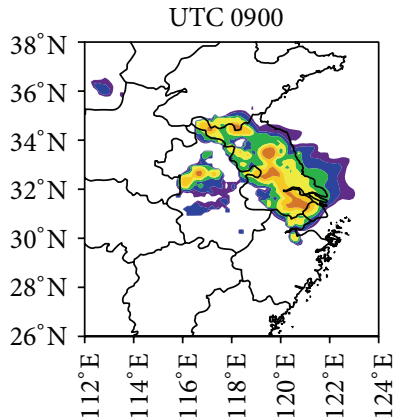

UTC 1000

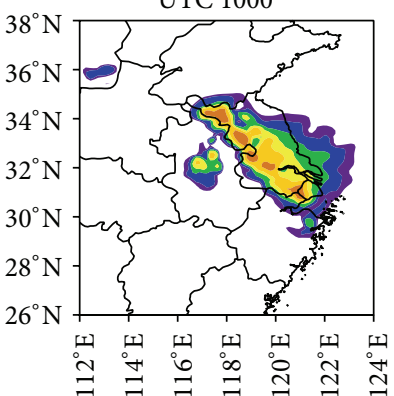

UTC 1100

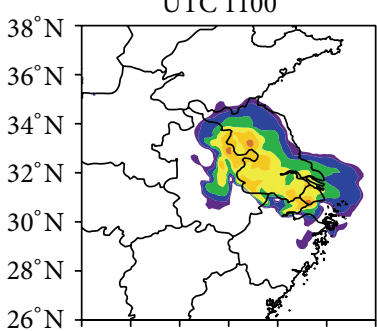

되 띠 되 디 되 되 더

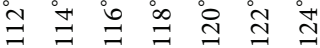

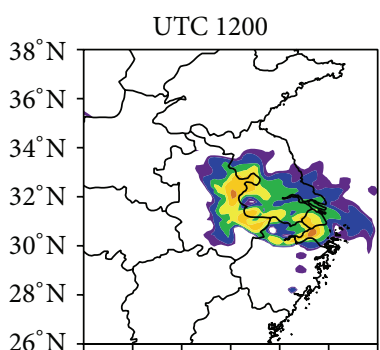

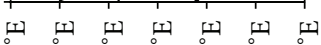

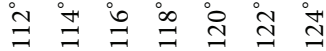

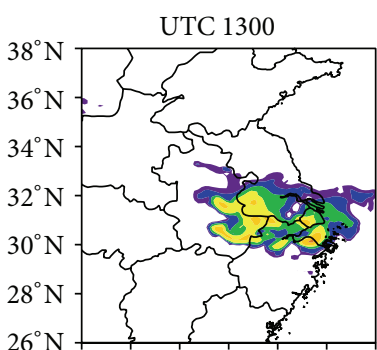

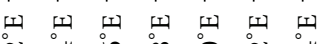

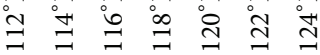



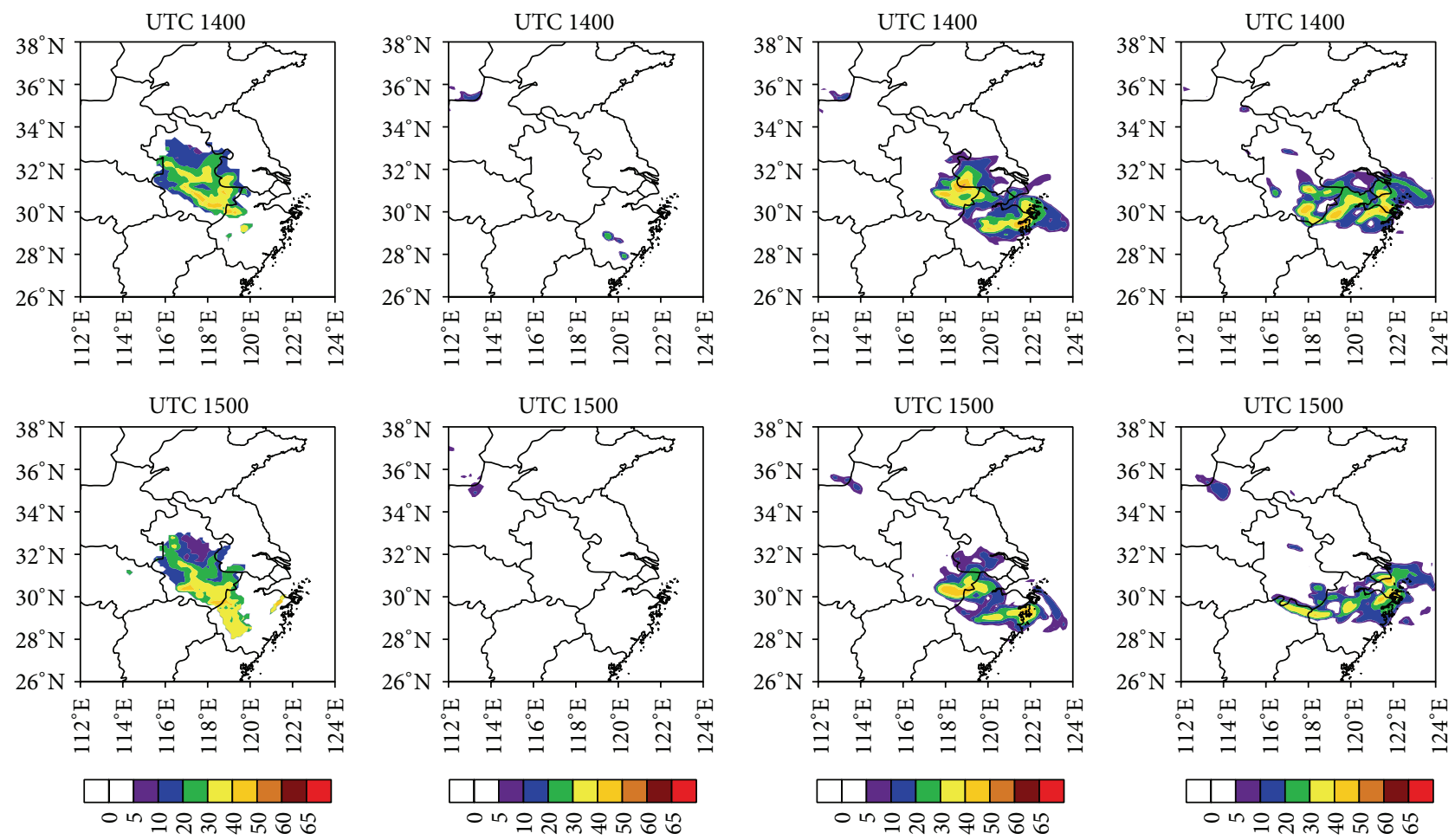

(b)

FIGURE 6: Hourly composite reflectivity from 0900 to 1500 UTC. Column 1 shows the observed radar composite reflectivity (dBZ), and columns 2-4 are the forecast composite reflectivity of Exp. CTL, Exp. lghtn, and Exp. radar, respectively.

radar were worse than those of Exp. lghtn. Generally, Exp. lghtn accurately forecast both the light rain threshold and rainstorm threshold, indicating that assimilating lightning location network data in the enhanced WRF-GSI system can achieve a significant improvement in 3 and $6 \mathrm{~h}$ precipitation forecasts. Based on the above analysis, properly decreasing the increments of perturbation potential temperature and of water vapor mixing ratio when assimilating observed radar reflectivity and lightning-proxy reflectivity leads to a greater improvement in both the composite reflectivity and precipitation over a few hours.

\section{Conclusions}

Lightning location data are an indicator of convective weather and can provide detailed information such as time, location, number, polarity, and intensity of discharge events that relate to convective clouds. Furthermore, lightning data are relatively unaffected by geographical constraints and exhibit higher temporal and spatial resolution than meteorological radar observations. Lightning location network data can thus play an important role in convective weather research and in particular can be a useful supplement to radar data in the initialization of refined weather forecasting. In the radar-enhanced WRF-GSI system, lightning location network data were first converted into 3D proxy radar reflectivity assuming a simple relationship between flash density and reflectivity. Then, the reflectivity information was used in a complex cloud analysis in the GSI system to improve the cloud/hydrometeor and moisture distributions. Additionally, the radar/lightning-proxy reflectivity was also simultaneously converted to a 3D temperature tendency field. Finally, the model-calculated temperature tendencies from the explicit microphysics scheme and the cumulus parameterization at 3D grid points where the radar temperature tendency was available were updated in the forward fullphysics step of diabatic digital filter initialization (DDFI) in the WRF-ARW3.4.1 core. In this study, three experiments were designed to test the system using an MCS case that occurred on June 5, 2009, assimilating Hefei Doppler radar and lightning data from Anhui Province. The conclusions of this study can be summarized as follows.

(1) There was a high correlation between the converted lightning-proxy reflectivity and Hefei Doppler radar observed reflectivity, with a correlation coefficient of 0.847 and a root mean square error of 6.062 .

(2) After cycled assimilation, the forecast composite reflectivity matched the observed reflectivity better than the parallel experiment without assimilation, and the maintained forecast composite reflectivity was perfect and could last for more than $6 \mathrm{~h}$, due to the correct relationship between variables in the radar-enhanced WRF-GSI system. 


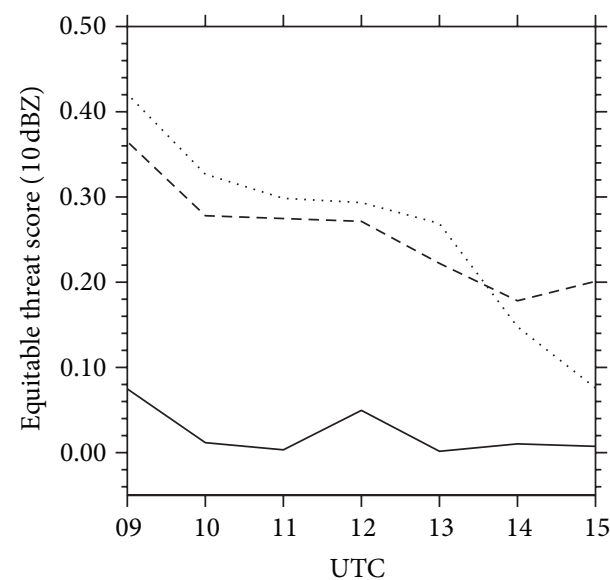

(a)

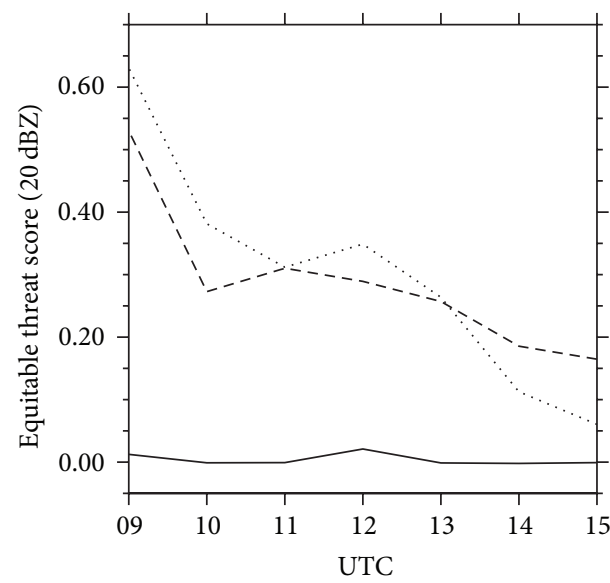

(c)

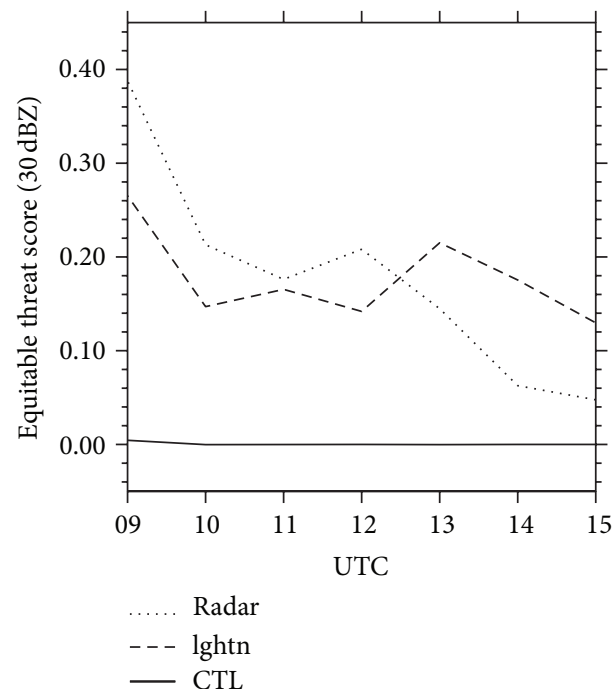

(e)

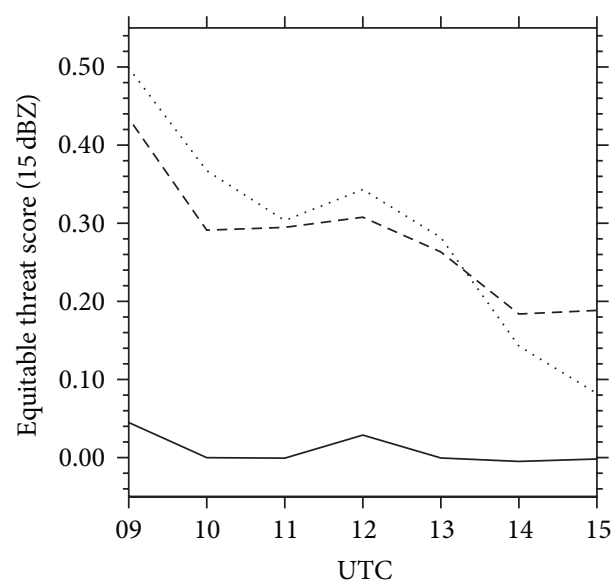

(b)

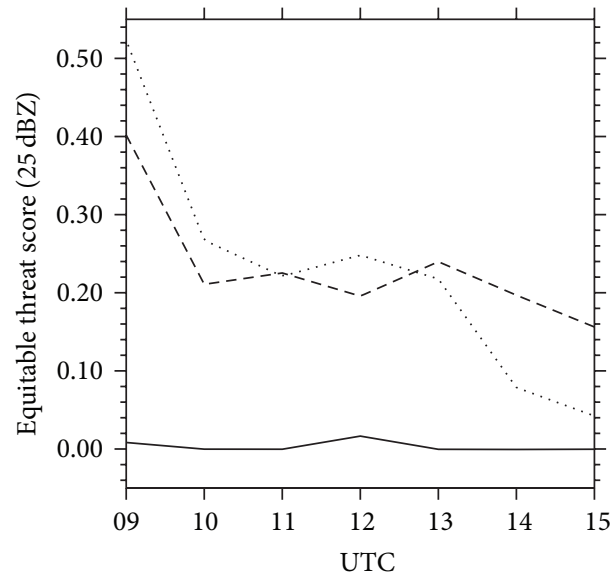

(d)

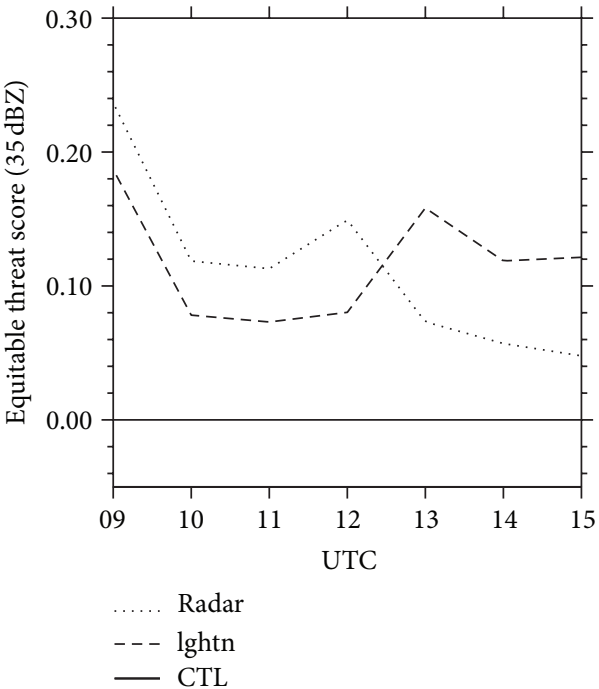

(f)

Figure 7: The ETS of the forecast composite reflectivity for Exp. CTL, Exp. lghtn, and Exp. radar at (a) 10, (b) 15, (c) 20, (d) 25, (e) 30, and (f) $35 \mathrm{dBZ}$. 

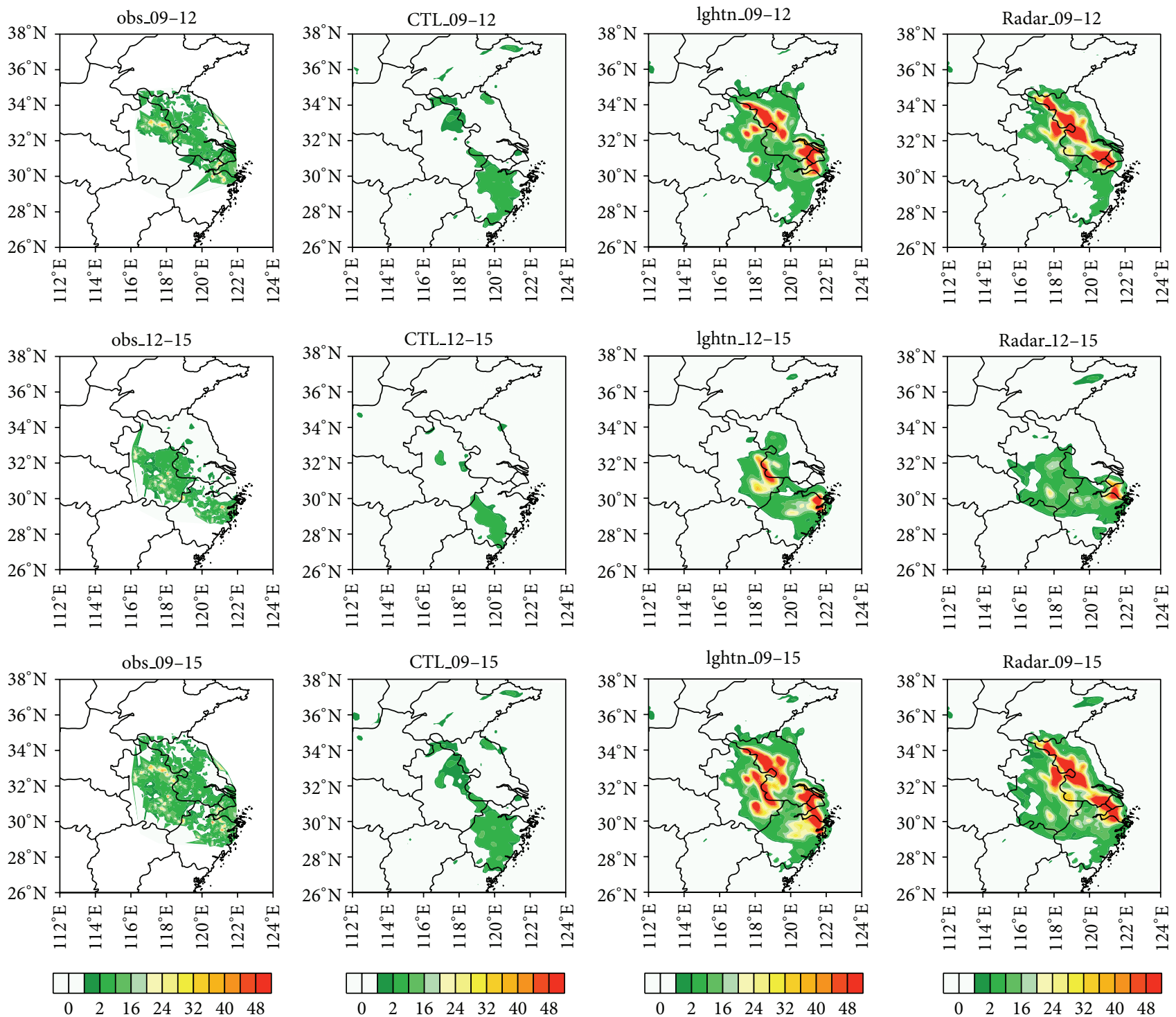

FIGURE 8: The forecast precipitation $(\mathrm{mm})$ for the three experiments over different time intervals. Column 1 shows the observed precipitation, and columns 2-4 the forecast precipitation from Exp. CTL, Exp. lghtn, and Exp. radar, respectively. The time interval of row 1 is $0900-1200$ UTC, and the time intervals of rows 2 and 3 are 1200-1500 UTC and 0900-1500 UTC, respectively.

(3) Assimilating lightning location network data in the enhanced WRF-GSI system can achieve a better improvement in 3 and $6 \mathrm{~h}$ precipitation forecasts than assimilating radar reflectivity data, although there is a shift in the spatial location and an overestimation of the precipitation intensity.

(4) Assimilating lightning location network data can give a better result because the area and intensity of lightning-proxy reflectivity were smaller than those of the observed radar reflectivity. Hence, the increments of perturbation potential temperature and of water vapor mixing ratio must be properly decreased when assimilating observed radar reflectivity and lightningproxy reflectivity. Based on the above conclusions, the revised radar-enhanced WRF-GSI system exhibited an excellent capacity for refined convective weather forecasting in a mesoscale NWP model after assimilating lightning location network data. However, there was an overestimation of the intensity of precipitation and a deviation in the spatial location in the first few hours of forecasting, which needs to be studied further so that the assimilation method can be revised and improved in the future.

\section{Conflict of Interests}

The authors declare that there is no conflict of interests regarding the publication of this paper. 


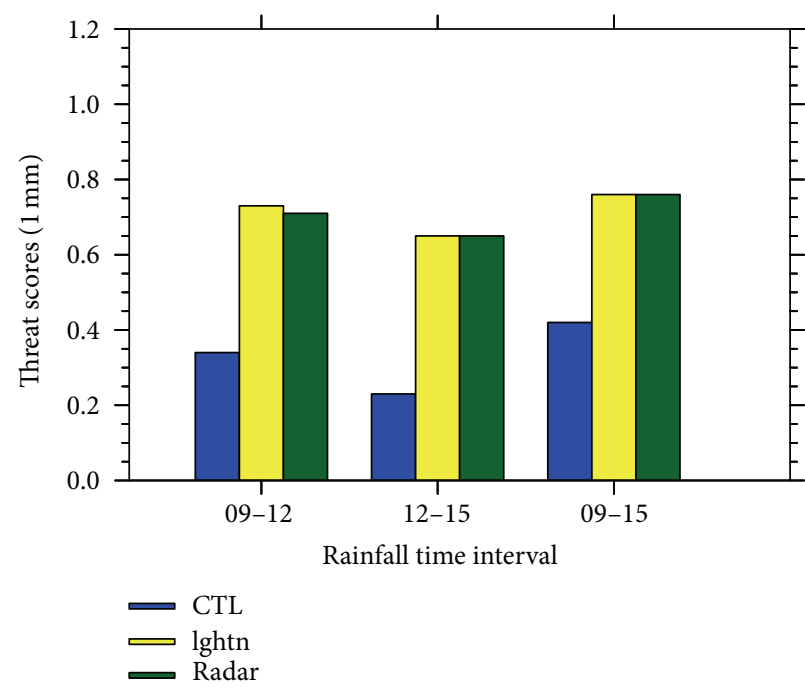

(a)

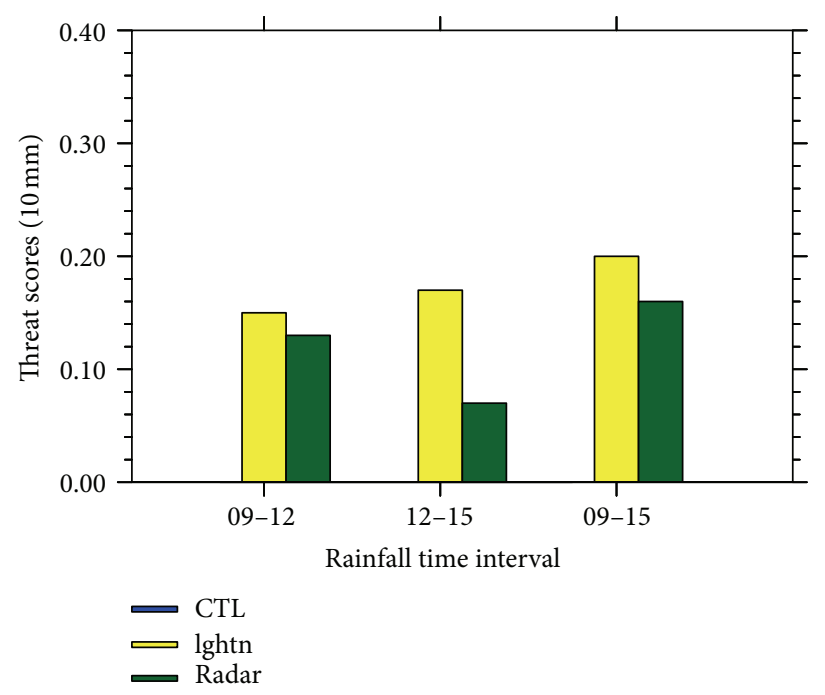

(b)

Figure 9: The threat scores of the three experiments for different precipitation thresholds: (a) $1 \mathrm{~mm}$ and (b) $10 \mathrm{~mm}$.

\section{Acknowledgments}

This research was supported by the National Key Basic Research Program of China (2014CB441406 and 2013CB430102) and the National Science Foundation of China (no. 41175092). The authors wish to thank the Weather Service Forecast Office of Anhui Province for providing radar and lightning data.

\section{References}

[1] Q. Xiao, Y. H. Kuo, J. Sun et al., "Assimilation of Doppler radar observations with a regional 3DVAR system: Impact of Doppler velocities on forecasts of a heavy rainfall case," Journal of Applied Meteorology, vol. 44, no. 6, pp. 768-788, 2005.

[2] J. Gao and D. J. Stensrud, "Assimilation of reflectivity data in a convective-scale, cycled 3DVAR framework with hydrometeor classification," Journal of the Atmospheric Sciences, vol. 69, no. 3, pp. 1054-1065, 2012.

[3] J. Gao, M. Xue, K. Brewster, and K. K. Droegemeier, "A threedimensional variational data analysis method with recursive filter for Doppler radars," Journal of Atmospheric and Oceanic Technology, vol. 21, no. 3, pp. 457-469, 2004.

[4] Z. Pu, X. Li, and J. Sun, "Impact of airborne doppler radar data assimilation on the numerical simulation of intensity changes of hurricane dennis near a landfall," Journal of the Atmospheric Sciences, vol. 66, no. 11, pp. 3351-3365, 2009.

[5] J. Sun and N. A. Crook, "Dynamical and microphysical retrieval from Doppler radar observations using a cloud model and its adjoint. Part I: model development and simulated data experiments," Journal of the Atmospheric Sciences, vol. 54, no. 12, pp. 1642-1661, 1997.

[6] J. Sun and N. A. Crook, "Dynamical and microphysical retrieval from doppler radar observations using a cloud model and its adjoint. Part II: retrieval experiments of an observed Florida convective storm," Journal of the Atmospheric Sciences, vol. 55, no. 5, pp. 835-852, 1998.
[7] M. Tong and M. Xue, "Ensemble Kalman filter assimilation of Doppler radar data with a compressible nonhydrostatic model: OSS experiments," Monthly Weather Review, vol. 133, no. 7, pp. 1789-1807, 2005.

[8] J. Gao and M. Xue, "An efficient dual-resolution approach for ensemble data assimilation and tests with simulated Doppler radar data," Monthly Weather Review, vol. 136, no. 3, pp. 945963, 2008.

[9] M. Xue, M. Tong, and K. K. Droegemeier, "An OSSE framework based on the ensemble square root Kalman filter for evaluating the impact of data from radar networks on thunderstorm analysis and forecasting," Journal of Atmospheric and Oceanic Technology, vol. 23, no. 1, pp. 46-66, 2006.

[10] F. Zhang, C. Snyder, and J. Sun, "Impacts of initial estimate and observation availability on convective-scale data assimilation with an ensemble Kalman filter," Monthly Weather Review, vol. 132, no. 5, pp. 1238-1253, 2004.

[11] S. Benjamin, "Assimilation of lightning data into RUC model convection forecasting," in Proceedings of the 2nd Conference on Meteorological Applications of Lightning Data, Tucson, Ariz, USA, 2006, https://ams.confex.com/ams/Annual2006/techprogram/paper_105079.htm.

[12] S. Benjamin, S. S. Weygandt, J. M. Brown et al., "From the radar-enhanced RUC to the WRF-based Rapid Refresh," in Proceedings of the 18th Conference on Numerical Weather Prediction, J3.4, Park City, Utah, USA, 2007.

[13] M. Hu, S. Weygandt, S. Benjamin et al., "Ongoing development and testing of generalized cloud analysis package within gsi for initializing rapid refresh," in Proceedings of the 13th Conference on Aviation, Range and Aerospace Meteorology, American Meteorology Society, New Orleans, Lo, USA, 2008.

[14] M. Hu, "Assimilation of lightning data using cloud analysis within the Rapid Refresh," in Proceedings of the 4th Conference on the Meteorological Applications of Lightning Data, p. 29, American Meteorology Society, Phoenix, Ariz, USA, January 2009, https://ams.confex.com/ams/89annual/techprogram/paper_150405.htm. 
[15] S. S. Weygandt, S. Benjamin, and J. Brown, "Radar reflectivitybased initialization of precipitation systems using a diabatic digital filter within the Rapid Update Cycle," in Proceedings of the 18th Conference on Numerical Weather Prediction, American Meteorology Society, Park City, Utah, USA, 2007.

[16] T. N. Krishnamurti, J. Xue, H. Bedi, and et al, "Physical initialization for numerical weather prediction over the tropics," Tellus B, vol. 43, no. 4, pp. 53-81, 1991.

[17] Y. Yang, C. J. Qiu, and J. D. Gong, "Physical initialization applied in WRF-Var for assimilation of Doppler radar data," Geophysical Research Letters, vol. 33, no. 22, Article ID L22807, 2006.

[18] Y. Wang, Y. Yang, and C. Wang, "Improving forecasting of strong convection by assimilating cloud-to-ground lightning data using the physical initialization method," Atmospheric Research, vol. 150, pp. 31-41, 2014.

[19] G. D. Alexander, J. A. Weinman, V. M. Karyampudi, W. S. Olson, and A. C. L. Lee, "The effect of assimilating rain rates derived from satellites and lightning on forecasts of the 1993 superstorm," Monthly Weather Review, vol. 127, no. 7, pp. 14331457, 1999.

[20] D.-E. Chang, J. A. Weinman, C. A. Morales, and W. S. Olson, "The effect of spaceborne microwave and ground-based continuous lightning measurements on forecasts of the 1998 groundhog day storm," Monthly Weather Review, vol. 129, no. 8, pp. 1809-1833, 2001.

[21] I. S. Brenner, "The relationship between meteorological parameters and daily summer rainfall amount and coverage in WestCentral Florida," Weather and Forecasting, vol. 19, no. 2, pp. 286300, 2004.

[22] W. A. Gallus Jr. and M. Segal, "Impact of improved initialization of mesoscale features on convective system rainfall in 10-km Eta simulations," Weather \& Forecasting, vol. 16, no. 6, pp. 680-696, 2001.

[23] A. Papadopoulos, E. Serpetzoglou, and E. N. Anagnostou, "Improving convective precipitation forecasting through assimilation of regional lightning measurements in a mesoscale model," Monthly Weather Review, vol. 135, no. 7, pp. 715-725, 2005.

[24] E. R. Mansell, C. L. Ziegler, and D. R. MacGorman, "A lightning data assimilation technique for mesoscale forecast models," Monthly Weather Review, vol. 135, no. 5, pp. 1732-1748, 2007.

[25] S. G. Benjamin, D. Dévényi, S. S. Weygandt et al., "An hourly assimilation-forecast cycle: the RUC," Monthly Weather Review, vol. 132, no. 2, pp. 495-518, 2004.

[26] M. Hu, M. Xue, and K. Brewster, "3DVAR and cloud analysis with WSR-88D level-II data for the prediction of the Fort Worth, Texas, tornadic thunderstorms. Part I: cloud analysis and its impact," Monthly Weather Review, vol. 134, no. 2, pp. 675-698, 2006.

[27] A. Papadopoulos, E. Serpetzoglou, and E. N. Anagnostou, "Evaluating the impact of lightning data assimilation on mesoscale model simulations of a flash flood inducing storm," Atmospheric Research, vol. 94, no. 4, pp. 715-725, 2009.

[28] G. Geernaert, S. Businger, C. Jeffery, T. Dunn, R. Elsberry, and D. Macgorman, "Using novel lightning data and advanced modeling approaches to predict maritime cyclogenesis," Bulletin of the American Meteorological Society, vol. 91, no. 8, pp. 1091-1093, 2010.

[29] A. T. Pessi and S. Businger, "Relationships among lightning, precipitation, and hydrometeor characteristics over the North Pacific Ocean," Journal of Applied Meteorology and Climatology, vol. 48, no. 4, pp. 833-848, 2009.
[30] A. O. Fierro, J. Gao, C. L. Ziegler, E. R. Mansell, D. R. Macgorman, and S. R. Dembek, "Evaluation of a cloud-scale lightning data assimilation technique and a 3DVAR method for the analysis and short-term forecast of the 29 june 2012 derecho event," Monthly Weather Review, vol. 142, no. 1, pp. 183-202, 2014.

[31] G. Thompson, R. M. Rasmussen, and K. Manning, "Explicit forecasts of winter precipitation using an improved bulk microphysics scheme, part I: description and sensitivity analysis," Monthly Weather Review, vol. 132, no. 2, pp. 519-542, 2004.

[32] B. S. Ferrier, "A double-moment multiple-phase four-class bulk ice scheme. Part I: description," Journal of the Atmospheric Sciences, vol. 51, no. 2, pp. 249-280, 1994.

[33] B. S. Ferrier, W.-K. Tao, and J. Simpson, "A double-moment multiple-phase four-class bulk ice scheme. Part II: simulations of convective storms in different large-scale environments and comparisons with other bulk parameterizations," Journal of the Atmospheric Sciences, vol. 52, no. 8, pp. 1001-1033, 1995.

[34] E. Kessler, "On the distribution and continuity of water substance in atmospheric circulations," Meteorological Monographs, vol. 10, no. 32, p. 88, 1969.

[35] Y.-L. Lin, R. D. Farley, and H. D. Orville, "Bulk parameterization of the snow field in a cloud model," Journal of Climate and Applied Meteorology, vol. 22, no. 6, pp. 1065-1092, 1983.

[36] E. J. Mlawer, S. J. Taubman, P. D. Brown, M. J. Iacono, and S. A. Clough, "Radiative transfer for inhomogeneous atmospheres: RRTM, a validated correlated-k model for the longwave," Journal of Geophysical Research D: Atmospheres, vol. 102, no. 14, pp. 16663-16682, 1997.

[37] M.-D. Chou and M. J. Suarez, "A solar radiation parameterization for atmospheric studies," NASA Tech. Memo 104606, 1999.

[38] Z. I. Janjić, "Nonsingular implementation of the Mellor-Yamada level 2.5 scheme in the NCEP Meso model," NCEP office note 437, 2002.

[39] G. L. Mellor and T. Yamada, "Development of a turbulence closure model for geophysical fluid problems," Reviews of Geophysics \& Space Physics, vol. 20, no. 4, pp. 851-875, 1982.

[40] T. G. Smirnova, J. M. Brown, and S. G. Benjamin, "Performance of different soil model configurations in simulating ground surface temperature and surface fluxes," Monthly Weather Review, vol. 125, no. 8, pp. 1870-1884, 1997.

[41] G. A. Grell and D. Dévényi, "A generalized approach to parameterizing convection combining ensemble and data assimilation techniques," Geophysical Research Letters, vol. 29, no. 14, pp. 381-38-4, 2002.

[42] L. S. Gandin and A. H. Murphy, "Equitable skill scores for categorical forecasts," Monthly Weather Review, vol. 120, no. 2, pp. 361-370, 1992. 

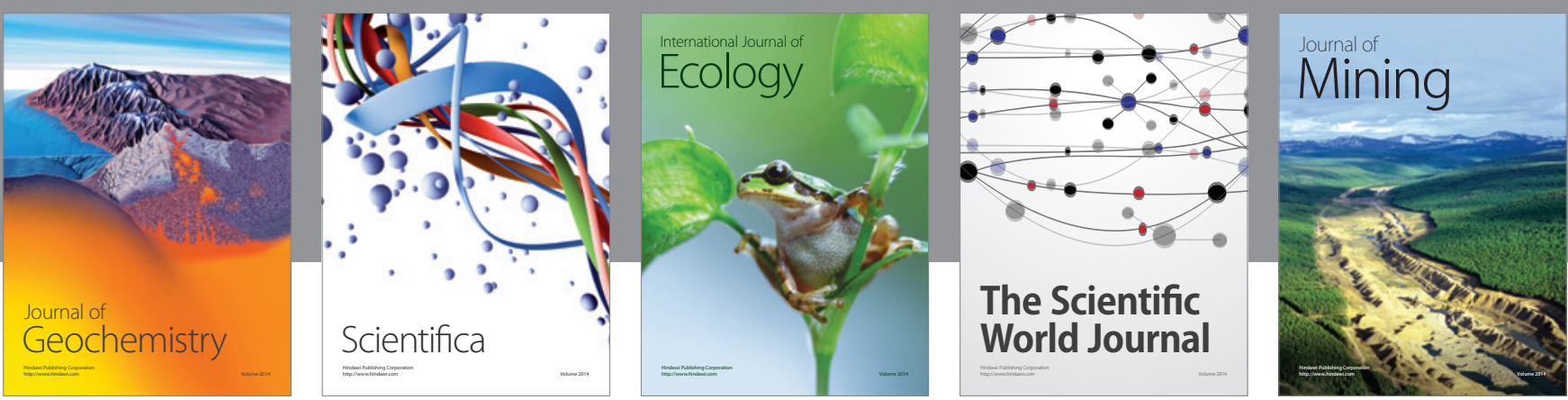

The Scientific World Journal
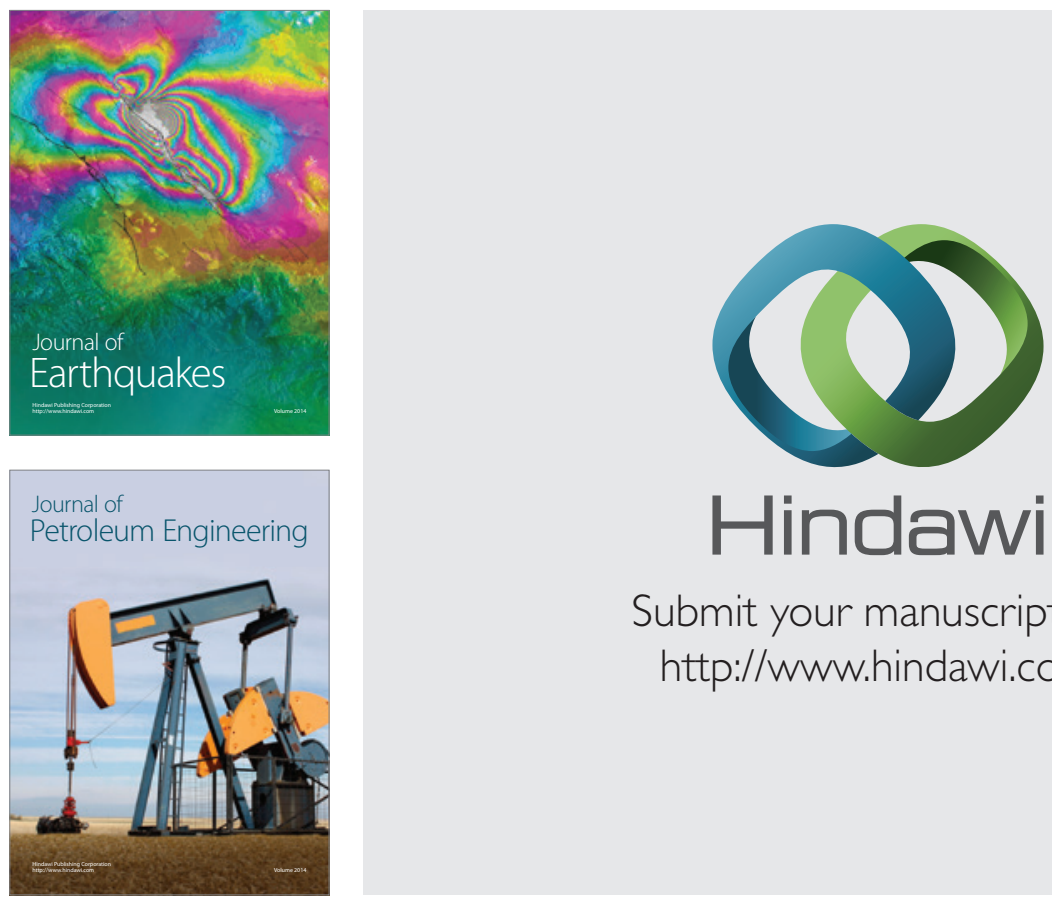

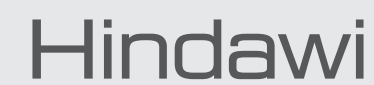

Submit your manuscripts at

http://www.hindawi.com
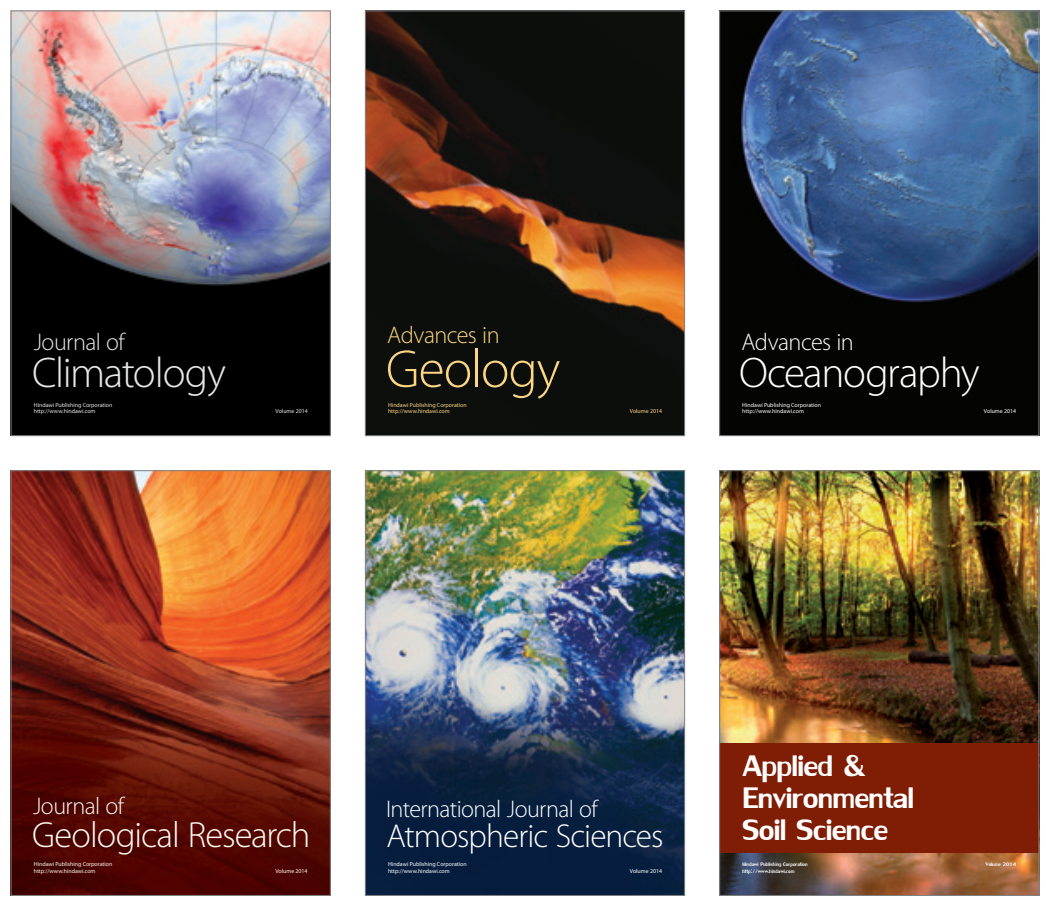
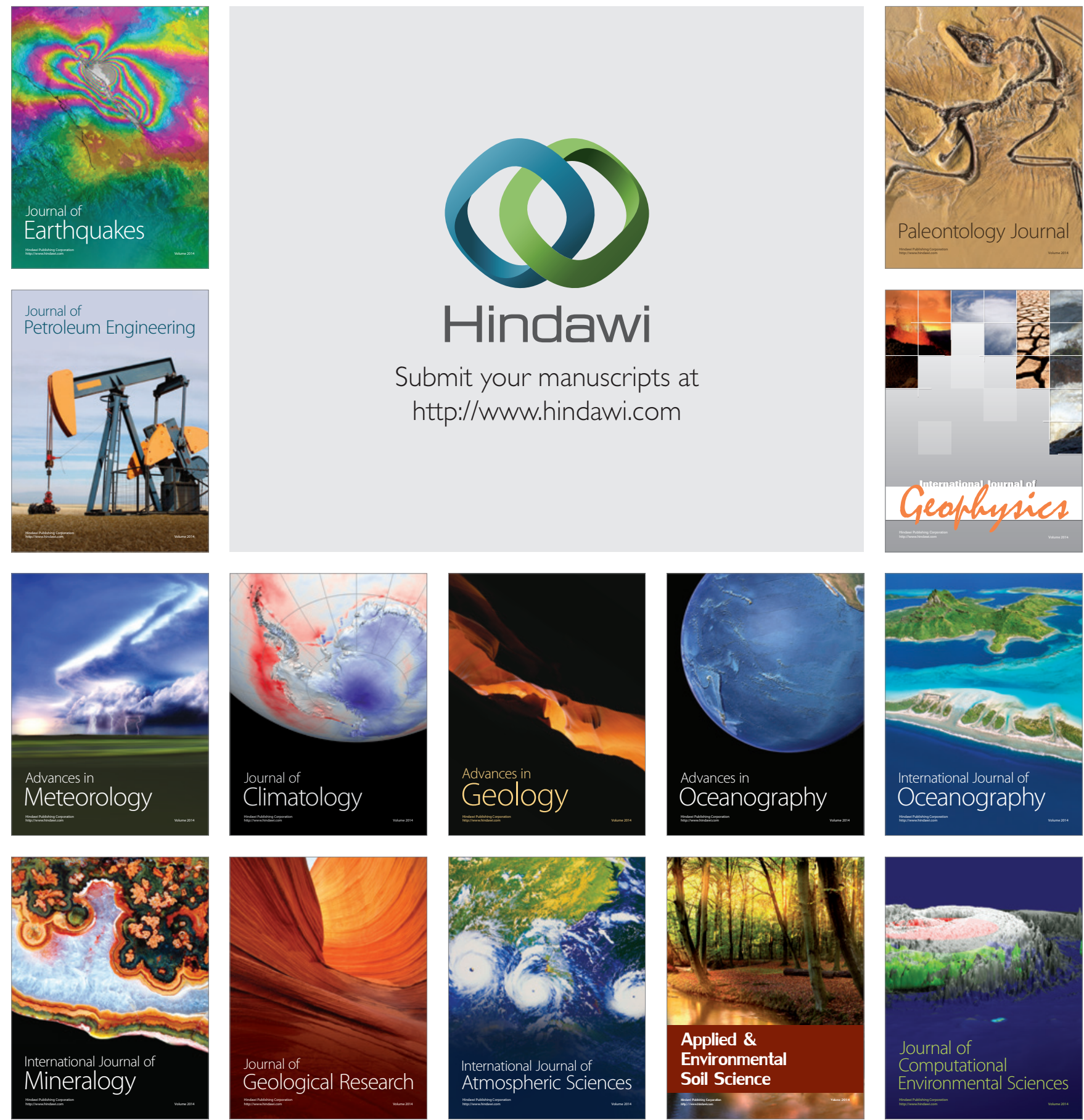